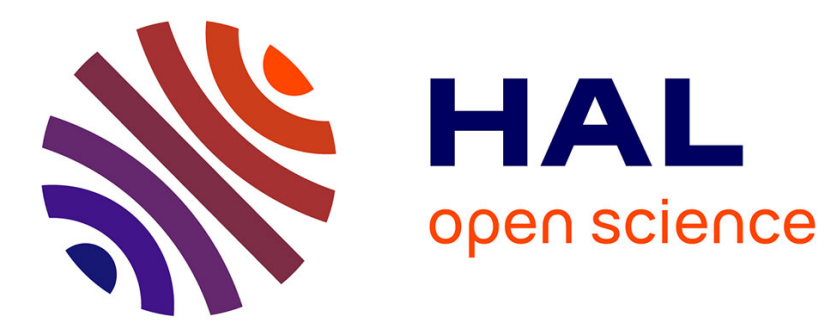

\title{
Mechanisms of interannual- to decadal-scale winter Labrador Sea ice variability
}

Sally Close, Christophe Herbaut, Marie-Noëlle Houssais, Anne-Cécile Blaizot

\section{To cite this version:}

Sally Close, Christophe Herbaut, Marie-Noëlle Houssais, Anne-Cécile Blaizot. Mechanisms of interannual- to decadal-scale winter Labrador Sea ice variability. Climate Dynamics, 2018, 51 (78), pp.2485-2508. 10.1007/s00382-017-4024-z . hal-01668778

\section{HAL Id: hal-01668778 \\ https://hal.sorbonne-universite.fr/hal-01668778}

Submitted on 20 Dec 2017

HAL is a multi-disciplinary open access archive for the deposit and dissemination of scientific research documents, whether they are published or not. The documents may come from teaching and research institutions in France or abroad, or from public or private research centers.
L'archive ouverte pluridisciplinaire HAL, est destinée au dépôt et à la diffusion de documents scientifiques de niveau recherche, publiés ou non, émanant des établissements d'enseignement et de recherche français ou étrangers, des laboratoires publics ou privés. 


\title{
Mechanisms of interannual- to decadal-scale winter Labrador Sea ice variability
}

\author{
S. Close • C. Herbaut • M.-N. Houssais • A.-C. Blaizot
}

\begin{abstract}
The variability of the winter sea ice cover of the Labrador Sea region and its links to atmospheric and oceanic forcing are investigated using observational data, a coupled ocean-sea ice model and a fully-coupled model simulation drawn from the CMIP5 archive. A consistent series of mechanisms associated with high sea ice cover are found amongst the various data sets. The highest values of sea ice area occur when the northern Labrador Sea is ice covered. This region is found to be primarily thermodynamically forced, contrasting with the dominance of mechanical forcing along the eastern coast of Baffin Island and Labrador, and the growth of sea ice is associated with anomalously fresh local ocean surface conditions. Positive fresh water anomalies are found to propagate to the region from a source area off the southeast Greenland coast with a 1 month transit time. These anomalies are associated with sea ice melt, driven by the enhanced offshore transport of sea ice in the source region, and its subsequent westward transport in the Irminger Current system. By combining sea ice transport through the Denmark Strait in the preceding autumn with the Greenland Blocking Index and the Atlantic Multidecadal Oscillation Index, strong correlation with the Labrador Sea ice area of the following winter is obtained. This relationship represents a dependence on the availability of sea ice to be melted
\end{abstract}

The research leading to these results has received funding from the European Union 7th Framework Programme (FP7 2007-2013) under grant agreement 308299, NACLIM Project.

S. Close, C. Herbaut, M.-N. Houssais and A.-C. Blaizot Sorbonne Universités (UPMC, Univ Paris 06)-CNRS-IRDMNHN,

LOCEAN Laboratory,

4 place Jussieu,

F-75005 Paris,

France E-mail: sally.close@univ-grenoble-alpes.fr in the source region, the necessary atmospheric forcing to transport this offshore, and a further multidecadalscale link with the large-scale sea surface temperature conditions.

Keywords Labrador Sea · sea ice · ice-oceanatmosphere interaction

\section{Introduction}

The Labrador Sea is a site of deep oceanic convection, supplying ca. $30 \%$ of the volume flux of the lower limb of the Atlantic Meridional Overturning Circulation (Talley et al, 2003) via the formation of Labrador Sea Water associated with this process. Physical mechanisms influencing the upper ocean stratification of the region are thus of particular interest, since they may implicate changes in the global ocean circulation and thus climate (e.g. Hodson and Sutton, 2012, Roberts et al, 2013, Robson et al, 2014; Jackson et al, 2016), although this view is disputed by some authors (e.g. Pickart and Spall, 2007; Lozier, 2012). A link between increased Arctic freshwater flux and decreased convection in the Labrador Sea has previously been suggested by numerical (Jungclaus et al, 2005) and analytical (Kuhlbrodt et al, 2001) models and also by observationbased studies (Yang et al, 2016). Sea ice can also modulate oceanic convection, either directly, by modifying the air-sea fluxes that are crucial to its onset (Marshall et al, 1998, Bitz et al, 2005), or indirectly, by preconditioning the upper water column (Visbeck et al, 1995. Marshall and Schott, 1999, Fenty and Heimbach, 2013). Certain authors have suggested that the "Great Salinity Anomalies" of the 1980s and 1990s were formed in the Labrador Sea (Belkin et al, 1998; Häkkinen, 2002), be- 
fore being propagated widely across the North Atlantic (Belkin, 2004).

The sea ice cover of the Labrador Sea undergoes strong variability at both interdecadal and interannual time scales (e.g. Deser et al, 2002). A dipole connection with the variability of the Barents Sea, inferred primarily from empirical orthogonal function (EOF) analyses of the sea ice concentration of the full Arctic region, has been suggested by some authors, such that the Labrador and Barents Sea ice cover is suggested to vary in antiphase (Walsh and Johnson, 1979; Fang and Wallace, 1994, Slonosky et al, 1997, Deser et al, 2000), driven by the North Atlantic Oscillation (NAO). However, recent studies note that this relationship is strongly dependent on the period of analysis (Close et al, 2017), and that the Labrador Sea ice cover varies independently of that of the other marginal seas on both multidecadal (Close et al, 2015) and interannual time scales (Chen et al, 2016; Close et al, 2017).

The forcing of the Labrador Sea ice cover has previously been ascribed to various mechanisms, implicating both the ocean and atmosphere over a range of spatial scales. There has been much interest in the potential role of large-scale climatic modes in driving sea ice variability: in particular, numerous authors have highlighted a link with the NAO (Rogers and van Loon, 1979. Walsh and Johnson, 1979, Fang and Wallace, 1994 Mysak et al, 1996; Deser et al, 2000). However, several studies have also stressed that the NAO is not sufficient in itself to fully describe the local climatic variability (Moore et al, 2014, 2015), and Peterson et al (2015) find that a combination of the NAO and Atlantic Multidecadal Oscillation (AMO) indices best describes the sea ice variability in the region.

Aside from the context of climatic modes, a general connection between the Labrador Sea ice cover and atmospheric variability has been inferred, linked to (north)westerly winds that advect cold, dry continental air over the Labrador Sea and Baffin Bay region. It is hypothesized that these winds drive variability in the sea ice cover via a primarily thermodynamic influence, linked to the modulation of surface air temperature (Ikeda et al, 1988, Mysak et al, 1996, Deser et al, 2002, Peterson et al, 2015). Considering the role of wind-driven advection, Deser et al (2002) find that this is a much weaker contributor, explaining only approximately $8 \%$ of the variance, with Ikeda et al (1988) suggesting that sea ice cover anomalies originate in the north of the region, forced by low atmospheric temperatures and high wind speed, and are then carried south by the wind and oceanic currents.

Attempts to clarify the connection between oceanic and sea ice variability in the Labrador Sea have been hampered by the relative paucity of data in the region. Mysak and Manak (1989); Mysak et al (1990) and Slonosky et al (1997) examined the link between the great salinity anomaly of the 1970s and the sea ice cover of the region; they noted that salinity and sea ice tended to co-vary, but were not able to disentangle the lag relationship with the available data. Marsden et al (1991) built on this work, employing observational data alongside a simple statistical feedback model to argue that coherent structures emerged when salinity anomalies led those in sea ice, and that stable ocean stratification could enhance sea ice formation. A recent study by Fenty and Heimbach (2013) employing a regional ocean-ice state estimate found further support for this idea, noting that preconditioning by sea ice meltwater promoted more efficient advancement of the sea ice edge, and was influential in determining the overall sea ice area.

In this work, the processes driving the winter sea ice variability in the Labrador Sea will be examined using a combination of observational and model data; the role of both the ocean and atmosphere will be considered. Section 2 details the data used and methodology. In section 3 , the principal pattern of sea ice variability is presented, and the ice budget decomposed to investigate the spatial variability. Links to atmospheric and oceanic variability are considered in section 4 , and the results placed into a longer term context in section 5 . We conclude with a discussion of the proposed mechanism of variability and its implications, and a summary of our principal conclusions in sections 6 and 7. Our primary result is that inter- to multiannual Labrador Sea ice variability is controlled by a sequence of events that are initiated by strong local westerly winds that melt sea ice along the south east Greenland coast, leading to an increased transport of freshwater to the Labrador Sea and modulating the local stratification and sea ice formation. This may have implications both for oceanic convection and local ocean-ice-atmosphere feedbacks.

\section{Data and Methods}

Considering first the observational data, the sea ice data used in this analysis are the monthly National Snow and Ice Data Center (NSIDC) bootstrap sea ice concentration (SIC) (Comiso, 2000, updated 2014), retrieved from the Nimbus-7 Scanning Multichannel Microwave Radiometer and Defense Meteorological Satellite Program (-F8, -F11 and -F13) and Special Sensor Microwave Imager (-F17) passive microwave measurements (hereafter referred to as SSMI). The data have a spatial resolution of $25 \mathrm{~km}$ and cover the period 1979-2013. Sea ice motion is analysed using the 
monthly NSIDC Polar Pathfinder ice motion product (the monthly means being created from the daily temporal resolution fields); the data set merges data from in situ buoys and satellite observations, resulting in a gridded product with a spatial resolution of $25 \mathrm{~km}$ (Tschudi et al, 2016). These data are available from the autumn of 1978 onwards. Throughout, we analyse the winter data, corresponding to the January-March (JFM) mean; these months were selected after prior analysis of the ice cover in the region, to obtain a period where the sea ice cover is present and the behaviour amongst the months is, on average, coherent.

Atmospheric fields are obtained from the European Centre for Medium-Range Weather Forecasts' ERA interim reanalysis (Dee et al, 2011, hereafter referred to as ERAi), covering the period 1979-present. Sea surface temperature is analysed using NOAA Optimum Interpolation Sea Surface Temperature (OISST) V2 (Reynolds et al, 2007). To examine the sea ice and atmospheric variability in a longer-term context, we also analyse data from the ECMWF ERA-20C reanalysis (Poli et al, 2016). The data are available over 19002010. However, examination of the sea ice record reveals that sea ice concentration exhibits very low variance prior to 1953 in this analysis, perhaps due to the very few observations that are available for assimilation prior to this time; since it is unclear whether or not this early part of the record is physically plausible, we choose to analyse only the 1953-2010 period in this work. The sea ice product assimilated by the reanalysis is HadISSTv2, which incorporates the European Organisation for the Exploitation of Meteorological Satellites (EUMETSAT) Ocean and Sea Ice Satellite Application Facility (OSI SAF) v1 reprocessed passive microwave product; full details can be found in Titchner and Rayner (2014). We also employ the monthly NAO index supplied by NOAA Climate Prediction Service (available from: http://www.cpc.ncep.noaa.gov/ products/precip/CWlink/pna/nao.shtml, derived from rotated EOF analysis on the $500 \mathrm{hPa}$ geopotential height) and the Atlantic Multidecadal Oscillation index of NOAA Earth System Research Laboratory (available from: https://www.esrl.noaa.gov/psd/data/timeseries/ $\mathrm{AMO} /$, based on SST).

In addition to the observational data, we analyse outputs from a 34 year model run covering the period 1979-2012, performed with a regional coupled sea iceocean model (Herbaut et al, 2015) based on NEMOLIM2 (Madec, 2008; Fichefet and Maqueda, 1997), to permit examination of terms for which no observations are available (e.g. thermodynamic components of the sea ice budget). The domain covers the Arctic Ocean and Atlantic region, from $30^{\circ} \mathrm{S}$ in the Atlantic to $50^{\circ} \mathrm{N}$ in the Pacific. The grid has 46 levels in the vertical, and a horizontal spacing that varies from $10 \mathrm{~km}$ in the Arctic to $25 \mathrm{~km}$ at the equator. The surface forcing is based on the daily ERA-interim reanalysis surface fields. A full description of the simulation is given in Herbaut et al (2015).

Finally, again with the aim of placing the results in a longer term context, we also analyse data from the MIROC4h model (Sakamoto et al, 2012), made available as part of the CMIP5 project (Taylor et al, 2011). The model output examined here is the r1i1p1 historical ensemble member (covering 1950-2005). This model is chosen both because it provides one of the highest spatial resolutions of the participating models $\left(0.28125^{\circ}\right.$ zonally $\mathrm{x} 0.1875^{\circ}$ meridionally for the eddy-permitting oceanic component, and $0.5625^{\circ}$ for the atmosphere) and for data availability reasons. We choose to analyse the "historical" experiment, with the hope of obtaining a system that responds with a variability analagous to that found in the observational record and obtained in our forced sea ice-ocean model simulation.

Low frequency (i.e. periods longer than interannual) variability is strongly evident in the time series examined in this work, so that the number of degrees of freedom of any given time series is often much smaller than the number of samples that comprise it. The effective number of degrees of freedom is hence calculated following Chelton (1983) (their eq. 1) and used here in the calculation of the significance level, taken as $95 \%$, throughout, to account for artificial skill. Unless otherwise stated, correlations are significant where values are given in the text. Whilst we will make much use of composite-based analyses to illustrate the difference between high and low ice states, this choice is made primarily to facilitate the visualisation and is not fundamental to the inferences made; complementary regression-based calculations that support the findings have been performed in all cases to assess the statistical significance of the results but, in the interests of brevity, are not always shown.

\section{Spatial and temporal variability of the winter sea ice}

\subsection{Mean state and temporal evolution}

The mean state and variance of the SSMI data over JFM 1979-2013 are shown in Figure 1a/b. In the mean state, Baffin and Hudson Bay have an ice cover that is close to $100 \%$, whilst in the Labrador Sea region, the ice coverage is high $(>80 \%)$ along the coast of Baffin Island and Labrador, but drops off rapidly towards the east (Figure 1 1 ), approximately following the line 

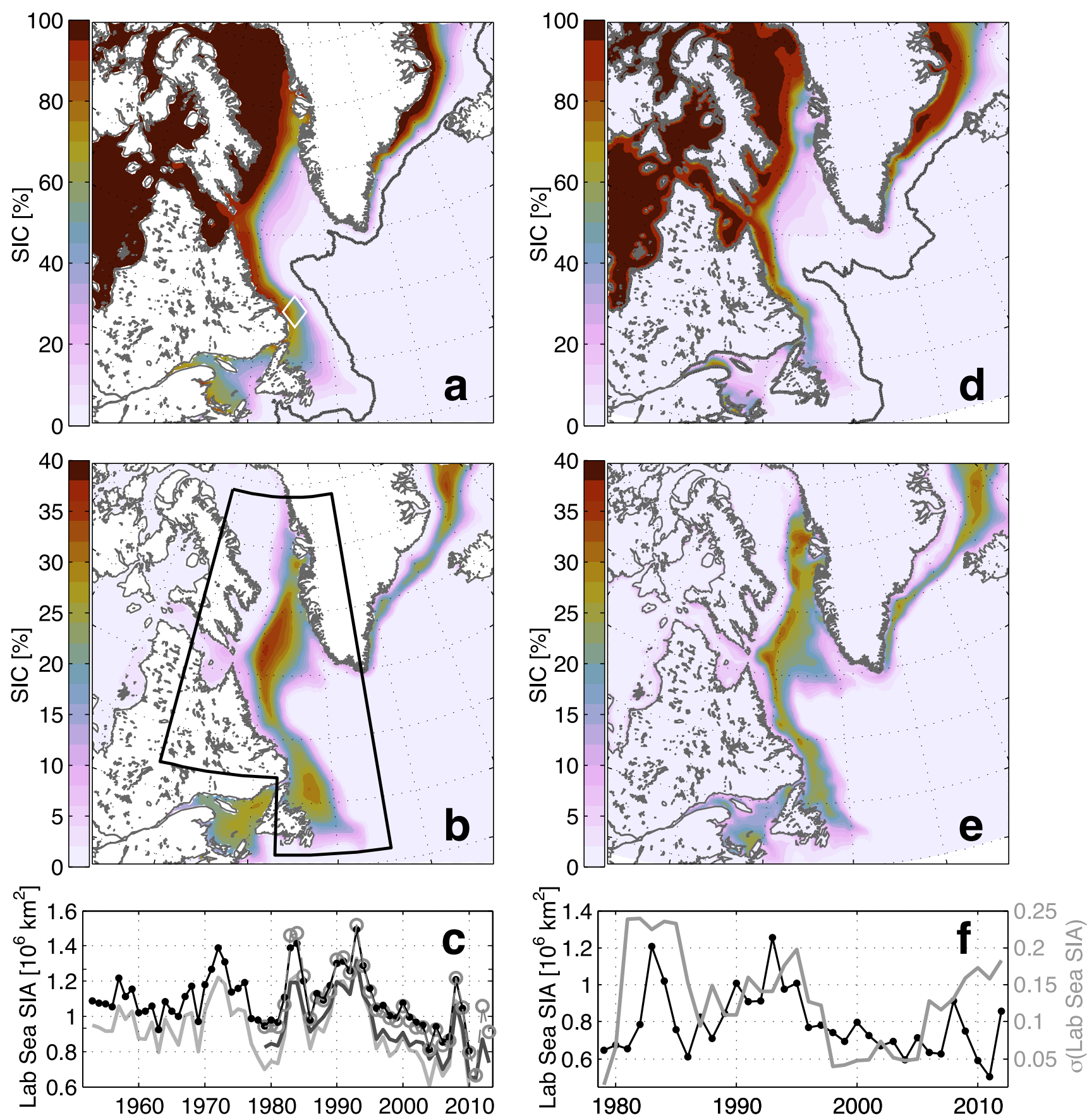

Fig. 1 (a) Mean JFM SIC using SSMI data. The thick grey line shows the maximum extent of the ice edge taken over the whole period (see text). The white diamond marks the position of Hamilton Bank, referred to in the main text. (b) Standard deviation of JFM SIC from SSMI data. The region outlined by the black box defines the area over which the regional SIA is calculated. (c) SIA of region outlined in panel (b) using ERA20C (thin black line / dots) and SSMI (thin grey line / circles) data. Thick lines show EOF mode 2 PC for ERA20C (light grey) and SSMI (dark grey). (d/e) as (a/b) but for sea ice-ocean model outputs. (f) Black line shows model SIA of Labrador Sea region as defined in (b), grey line shows the 5-year running standard deviation of the model SIA. 
of the continental shelf. Whilst the SIC contours are tightly spaced over approximately the $60-100 \%$ range, over the $0-40 \%$ range the SIC contours are much more widely spaced, indicating occasional large spatial expansions of the ice cover. The standard deviation provides further support for this idea: whilst the highest standard deviations in the Labrador Sea are found offshelf of Baffin Island (overlying approximately the 40$50 \%$ contours in the mean state), this pole of standard deviation nevertheless extends southeastwards parallel to the southwestern Greenland coast into a region of low mean SIC. The spatial pattern of the standard deviation suggests several individual poles of variability, notably a stronger, northern pole spanning the northwestern Labrador Sea, and a weaker, southern pole, spanning the southwestern Labrador Sea between Hamilton Bank (white diamond in Figure 1 a) and the eastern Newfoundland coast ${ }^{1}$. A distinct separation can be noted between these two poles, suggesting that they do not represent a single, coherent region of variability, but rather two independent regions. This hypothesis will be examined further below. Along the eastern coast of Greenland, a train of moderately high variability can be seen extending from the southern tip of Greenland along the mean ice edge, towards the region of high variability in the northeast.

The sea ice area (SIA) of the Labrador Sea region (defined by the black box outlined in Figure 1 $1 \mathrm{~b}$ ) is shown in Figure 11 for both SSMI and ERA20C. The time series contain a strong multiannual component, and the highest SIA states all occur as multiannual (i.e. more than one year duration) events. This is manifest over the SSMI (post-1979) period by two largeamplitude fluctuations, corresponding to increased sea ice cover, that occur over the winters 1983-4 and 1990-5, followed by a period characterised by a slow decreasing trend with weaker interannual variability over approximately 1996-2005. An increase in interannual variability is again evident after approximately 2008. Figure 1f shows the 5-year running standard deviation, highlighting this period of weaker interannual variability. The ERA20C SIA further suggests the presence of a third large-amplitude multiannual fluctuation over 1970-76, preceded by a period characterised by relatively weak interannual variability over 1953-1970.

In an EOF analysis of Arctic-wide winter (JFM) SIC using either SSMI or ERA-20C, the second mode of variability is associated with the Labrador Sea (Close

1 Further poles of variability are also evident in the Gulf of St. Lawrence, west of Newfoundland, and in the Greenland Sea, in the north east extreme of the domain shown in Figure 1 However, these two poles will not be discussed further in this work, as we will focus on the Labrador Sea region. et al, 2017), and explains significant variability only in this region. The loading pattern (not shown) has the same form as the standard deviation shown in Figure $1 \mathrm{~b}$, and the principal component associated with this mode (Figure 1 $\mathrm{c}$ ) is correlated with the Labrador Sea SIA with $r=0.97$. Since the Arctic-wide mode associated with the Labrador Sea does not explain significant variance in any other region (and, inversely, the other modes do not explain significant variance in the Labrador Sea), this suggests that the variability of the Labrador Sea ice is independent from that of the rest of the Arctic.

3.2 Mechanical and thermodynamical contributions to winter sea ice variability

To evaluate the relative contributions of mechanical and thermodynamical influences in determining the JFM sea ice variability, outputs from a coupled ocean-sea ice model (see section 2) are used. Validation of the model against SSMI data shows that, overall, the model reproduces the spatial and temporal patterns of variability (Figure 1) with reasonable accuracy, although the amplitude of the variability is underestimated in places. In the Labrador Sea, the main discrepancy is that the southern pole that is found in the standard deviation using SSMI is not well reproduced, since the ice cover is weaker in this region in the model. The distribution of the ice cover is otherwise well reproduced, with near $100 \%$ coverage in Baffin Bay and Hudson Bay, and high ice cover along the western side of the region that diminishes rapidly in the offshore direction (Figure 1/d/e). Because of the weaker ice cover along the Newfoundland coast, noted above, the Labrador Sea region model SIA has a mean offset of $-0.28 \times 10^{5} \mathrm{~km}^{2}(\sim 20 \%)$ relative to the equivalent calculation in SSMI and ERA-20C (Figure 1f/f). However, the interannual variability is well reproduced, with the time series being correlated with $r=0.93$ (same for both SSMI and ERA-20C over the periods common to each pair of time series).

Whilst observations provide a measure of the sea ice concentration, to evaluate the contribution of the thermodynamic / mechanical influences it is necessary to consider rather the full sea ice volume budget. In the model output, the ice in the Labrador Sea is generally relatively thin, with a mean thickness of $\sim 30 \mathrm{~cm}$ over the region used to calculated the SIA, and, after computation of the total sea ice volume time series over this same region, it is found that the SIA and sea ice volume time series are correlated with $r=0.95$. We thus assume that the ice volume variability here is also representative of variability in SIC. 

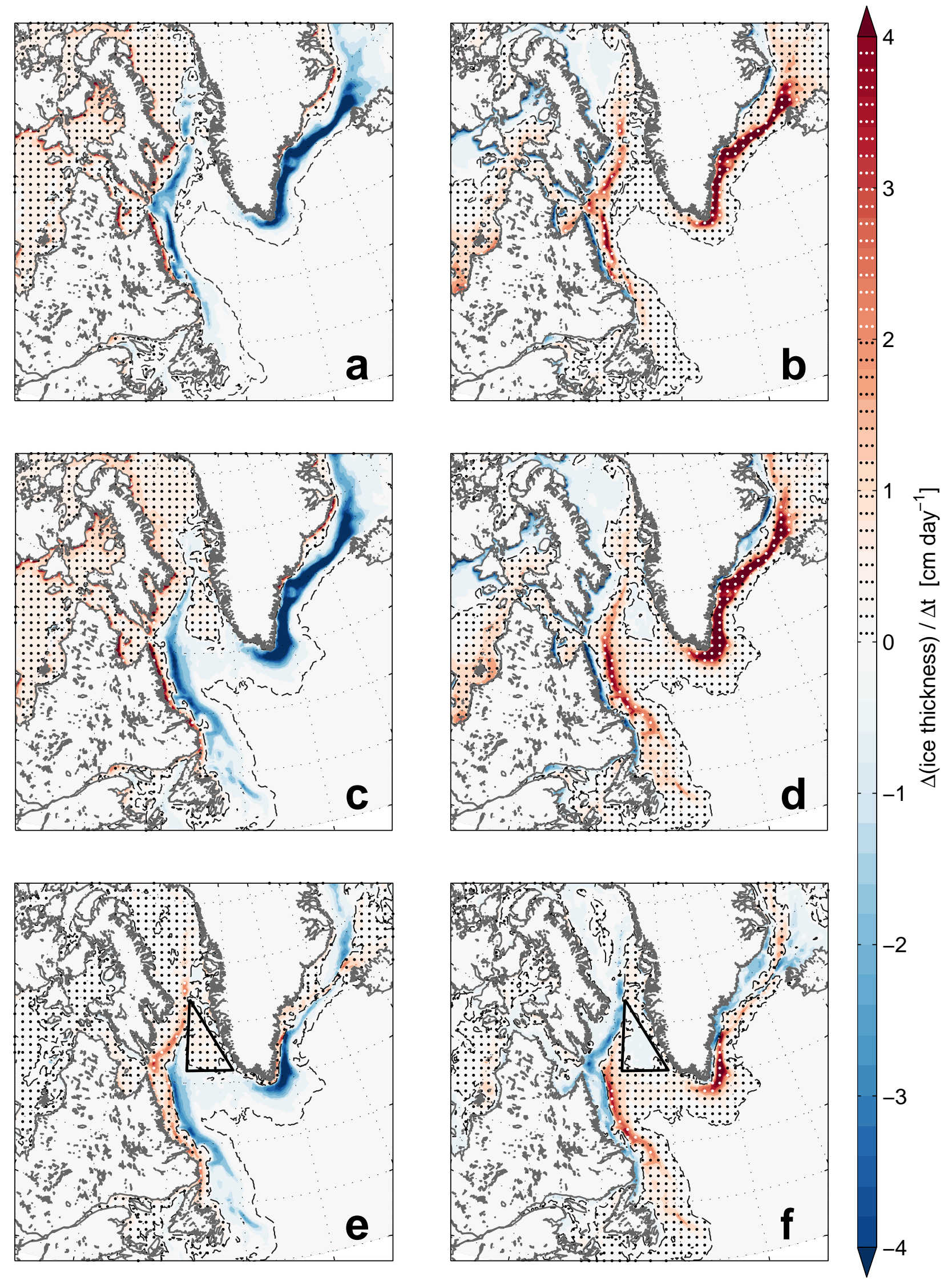

Fig. 2 (a) Lower quartile ice production composite. Throughout, the lower quartile, corresponding to low JFM SIA, comprises 1979, 1981, 1986, 2004, 2006, 2007, 2010 and 2011. (b) Lower quartile ice divergence composite. (c) Upper quartile ice production composite. Throughout, the upper quartile, corresponding to high JFM SIA, is composed of 1983, 1984, 1990, 1992, 1993, 1994, 1995 and 2008. (d) Upper quartile ice divergence composite. (e) Upper quartile composite minus lower quartile composite of ice production. (f) Upper quartile composite minus lower quartile composite of ice divergence. All composites use JFM data. The dashed black lines show the $0 \mathrm{~cm} /$ day contour. The black triangles in (e)/(f) highlight the region of anomalous production / divergence discussed in the text. 


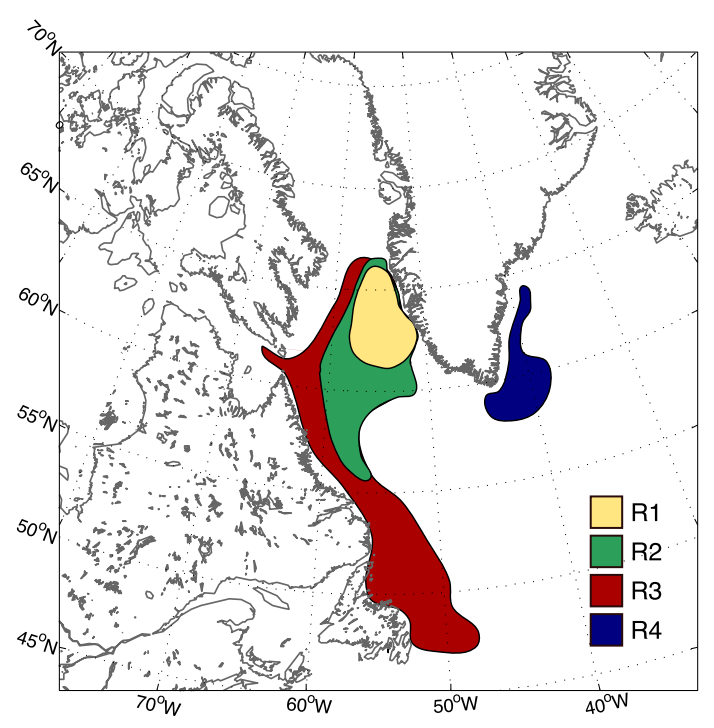

Fig. 3 Map showing the main subregions discussed and the numbering used to refer to them. Defined using model outputs, $\mathrm{R} 1$ is the region in which ice growth occurs during high ice years, and lies within R2, the northern subregion. R3 is referred to as the southern subregion (shown here only for that part of the region that experiences interannual variability, and thus which contributes to the variability of the time series). R4 is the region in which the sea ice melt that is transported as freshwater to R1 occurs.

Composites of the mean net sea ice production and divergence for the lower and upper quartiles of (model) SIA are shown in Figure 2, The large-scale pattern is, overall, quite similar between the years when the SIA is low (Figure 2a/b) and high (Figure 2//d), with ice production occurring in central/western Baffin Bay and across the Canadian Arctic Archipelago, accompanied by melt along the outer ice edge and mechanical export of ice away from the eastern Greenland and Labrador coasts in both cases. Nevertheless, a notable difference between the high and low ice composites can be seen in the northern Labrador Sea, where a region of ice production / export occurs in high SIA years (Figure 22-f, highlighted by the black triangle in Figure $2 \mathrm{e} / \mathrm{f}$. For reference, the main regions referred to in the text are shown schematically in Figure 3 , where we also define a numbering system that will be used throughout for clarity. We will denote this enhanced production region by $[R 1])$. Summing the two composite differences (i.e. Figure $2 \mathrm{e}+2$; , shown in Figure 4 a), the resultant field is positive over most of the domain (Figure 4a). Regions of ice production and convergence thus generally dominate over competing co-localised regions of divergence and melt respectively, yielding an increase in ice thickness (Figure 43) over most of the domain during years with higher ice cover.
To facilitate interpretation of the divergence composites, the mean state and difference between the high and low SIA ice composites of ice velocities are also considered. Both model and Polar Pathfinder data have been analysed; comparable results are obtained in both cases, and thus in the interests of brevity only model outputs will be presented. In the mean JFM state (Figure 5a), the highest ice velocities are found along the eastern coast of Greenland, associated with the East Greenland Current, with elevated velocities also being evident in the Baffin and Labrador currents. Velocities are generally weak outside of the areas noted above; in the Labrador Sea and along the ice edge and southern coast of Greenland, the regions where the mean velocity is weak have only intermittent ice cover, suggesting that these weak mean velocities reflect the sporadic ice presence at these locations, rather than slow drift speeds.

\subsection{Subregions of distinct variability}

To examine the influence of the thermodynamic subregion (i.e. R1, the region of enhanced ice growth identified in Figure 2, approximately corresponding to the black triangle shown thereon) in determining the overall SIA of the region, the subregion is isolated by selecting points with positive net production lying within the Labrador Sea and east of the band of production spanning the coastline. However, since, in the following analysis, comparisons will also be performed with SSMI and ERA20C data, for which the only available relevant parameter is SIC, it is necessary to translate this production-based criterion into an equivalent criterion based on SIC. Over the 1979-2012 period common to both the model and SSMI, and the 1979-2010 period common to the model and ERA20C, the SIC fields are thus regressed onto the time series of net ice production in this region [R1], and points that are significantly correlated within the region to the west of Greenland are used to calculate the SIA of this subregion [R2].

The SIA time series for the full region, the thermodynamic subregion defined using the above criterion [R2] and the difference between the two are shown in Figure 6d for the model output, and Figure SI1d for SSMI (for reference, the full region is defined by the black box in Figure 1 $\mathrm{b}$, and the points corresponding to the above subregion definition are shown by the thick black contours in Figures 6 and SI1 for the model output and SSMI respectively). In separating the thermodynamic subregion from the total SIA, it can be seen that the interannual-scale variability appears to be primary attributable to the variability of this region [R2], with the variance of the remainder time series being greatly reduced. This is confirmed by calculation of 

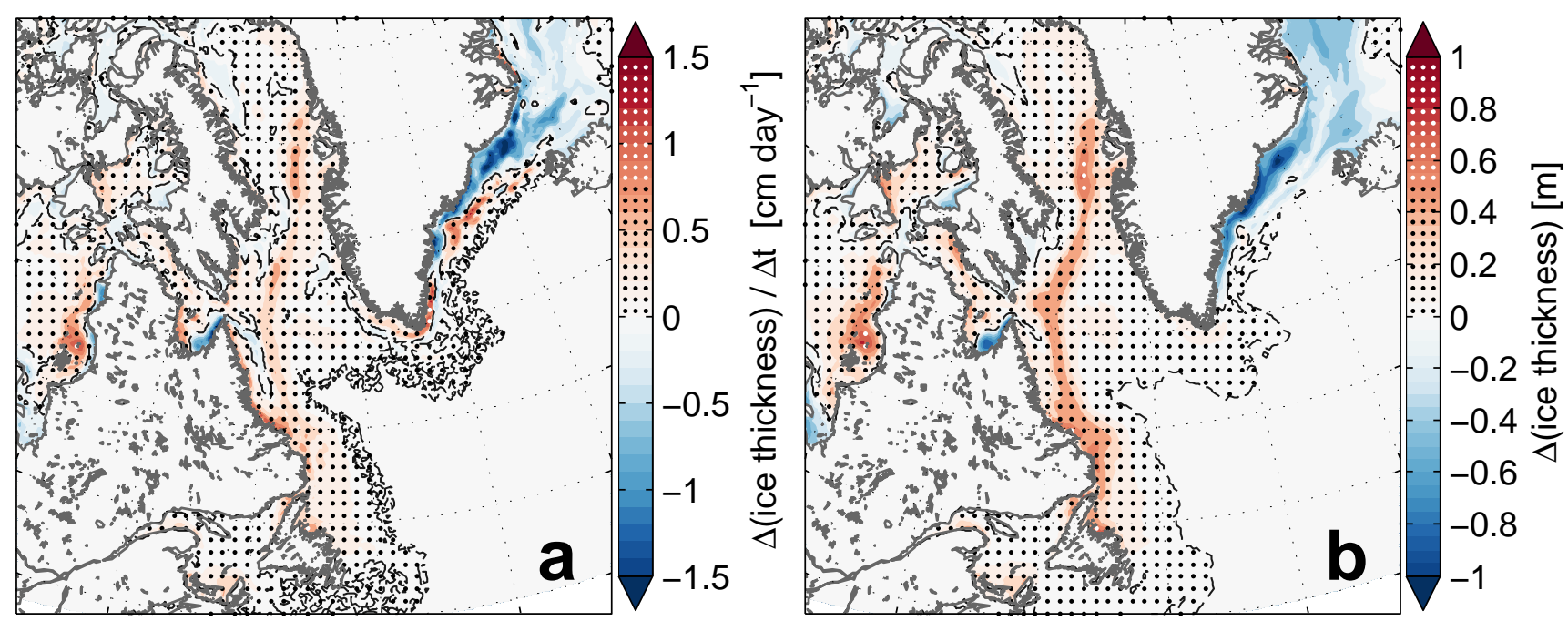

Fig. 4 (a) Sum of upper quartile composites minus lower quartile composites of ice production and ice divergence (i.e. Figure $2 p+2$;) (b) Upper quartile composite minus lower quartile composite of ice thickness. The dashed black lines show the 0 contours for both quantities. The quartiles are defined based on SIA, and comprise the years listed in Fig. 2.
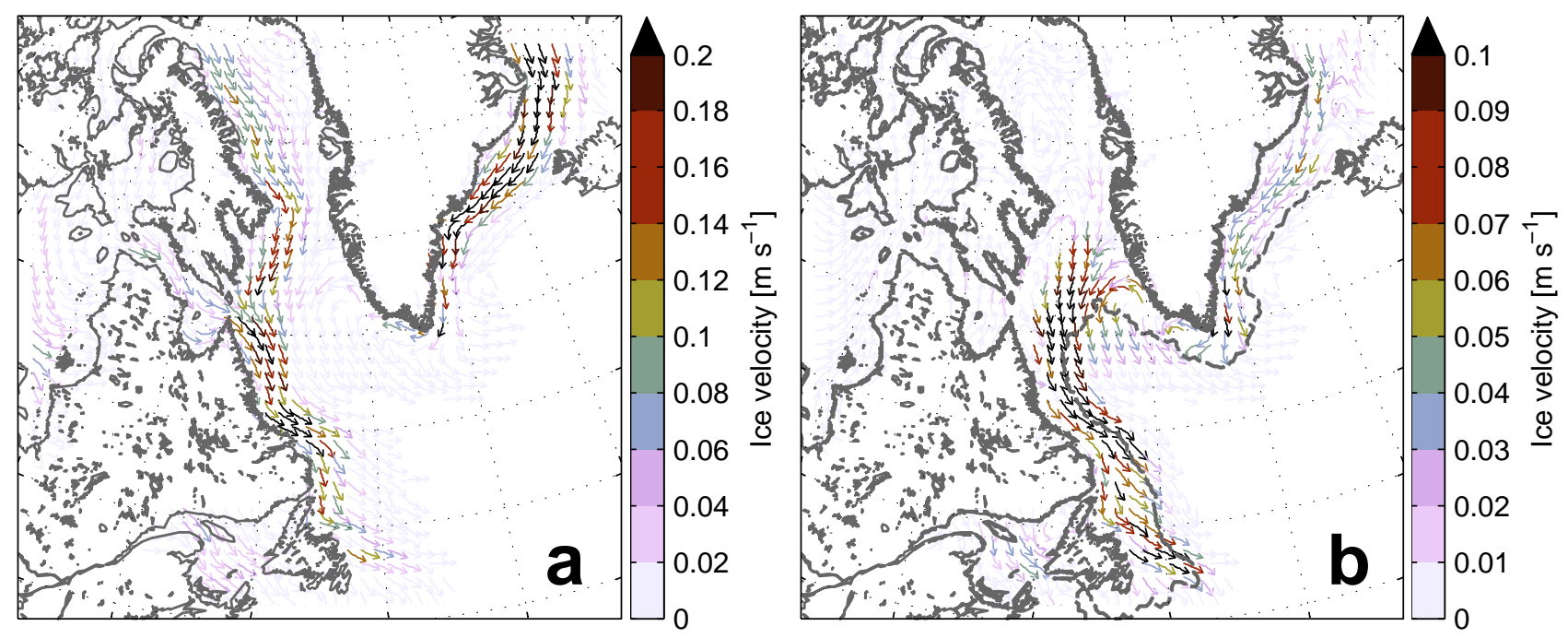

Fig. 5 (a) Mean JFM ice velocities from model. (b) Upper SIA quartile ice velocity composite minus lower SIA quartile ice velocity composite. The grey dashed line shows the $\mathrm{SIC}=0$ contour for the lower SIA quartile. The quartiles are defined based on SIA, and comprise the years listed in Fig. 2.

the standard deviation of the high-pass filtered time series (using a cutoff time of 2 years): the standard deviations for the three filtered (model) time series are $2.87 \times 10^{4} \mathrm{~km}^{2}$ for the total region, $1.92 \times 10^{4} \mathrm{~km}^{2}$ for the subregion and $1.05 \times 10^{4} \mathrm{~km}^{2}$ for the remainder. For ease of reference, the thermodynamic subregion and the remainder will hereafter be referred to as the northern and southern subregions, and correspond to regions R2 and R3 respectively in Figure 3 . Regression of the model and SSMI SIC on to the three time series (Figures $6 \mathrm{a}-\mathrm{c}$ and SI1a-c) confirms that the various time series explain the maximum variability in two different regions.
Despite the difference in location of the maximum, there is some overlap in the locations in which the two time series explain variance and, indeed, the SIA time series of the northern [R2] and southern [R3] subregions are strongly correlated, with $r=0.80$. Wavelet analysis (not shown) confirms that this correlation is significant only in the low frequency range (periods greater than 4 years), and that the two time series are not correlated at interannual time scales (confirmed by correlation analysis of the filtered time series of the two subregions, $\mathrm{r}=0.57 / 0.88$ for the high-/low-pass filtered series respectively using the model data with a cosine-Lanczos filter and a 4 year cutoff). This thus suggests a poten- 

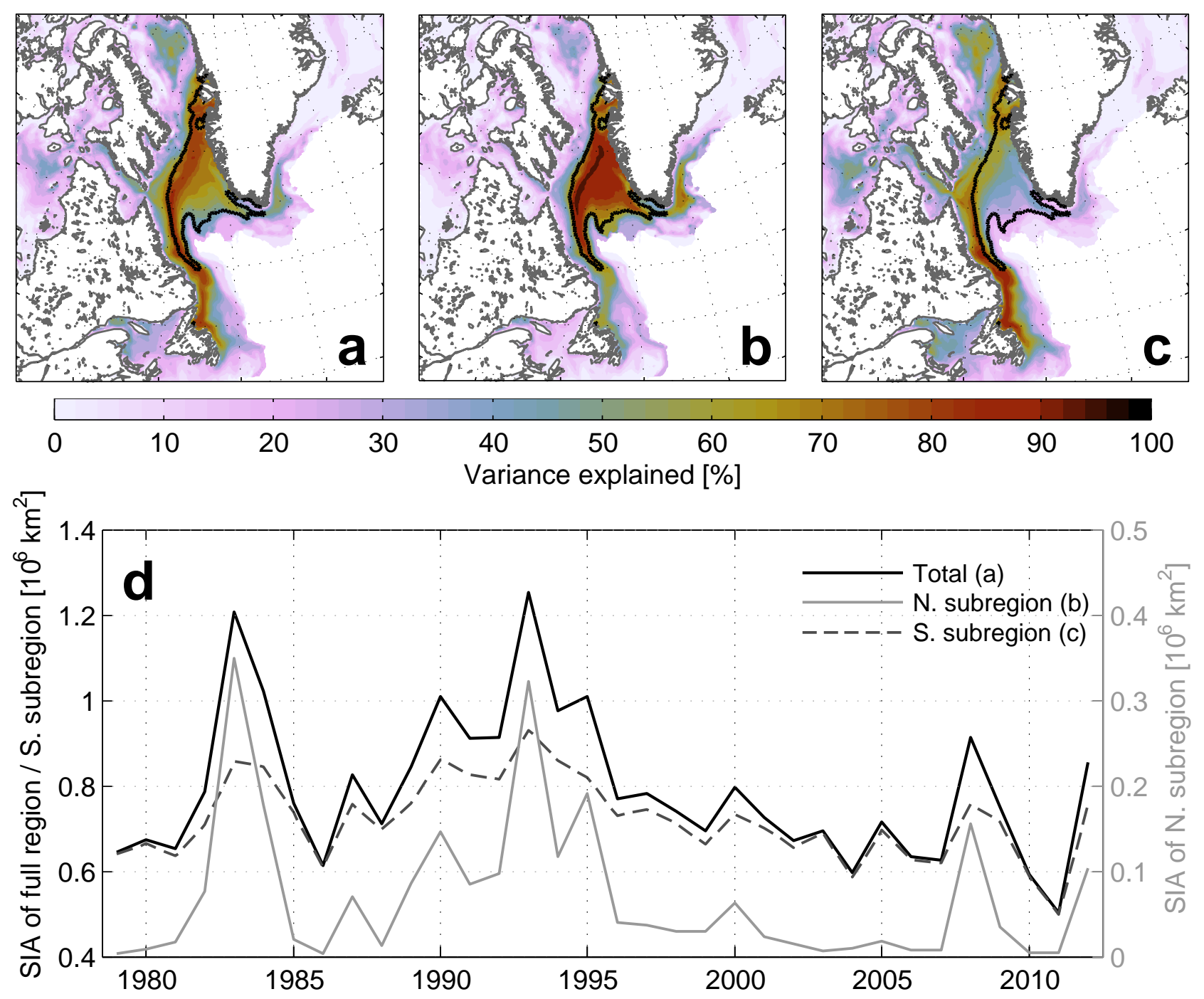

Fig. $6 \%$ of variance explained by regression of model SIC on to JFM SIA of (a) total region, (b) thermodynamically-influenced subregion [R2], (c) remainder obtained by subtracting SIA of subregion from total [R3]. (d) SIA time series used in regressions. In (a-c), the thick black contour shows the points used to define the northern subregion.

tial link between the two regions at low frequencies, but also, taken in combination with the analysis of the previous paragraph, highlights that the interannual variability is associated predominantly with the northern subregion [R2].

The difference between the high and low SIA composite ice velocities (Figure 5b) highlights a band of strongly increased velocities that transport ice southwestward away from the southwest Greenland coastal region in the northern Labrador Sea, then parallel to the Labrador coast and offshore adjacent to Newfoundland. These anomalies are consistent with the presence of a source of ice in the northern subregion [R2], and thus correspond to the anomalous production noted here during high SIA years in Figure 2e. Based on the model speeds obtained in the high SIA composite and the along-path distance, the transit time for ice formed in the northern subregion [R2] to reach the southern extent of the band of anomalously high ice velocity off southern Labrador is estimated to vary between three and five months, depending on the location of the beginning of the path. The transport out of the northern subregion is relatively slow (taking approximately 2.5 months), whilst along the coast of Labrador, the speeds are higher, suggesting a transit time of approximately 3 months between the Hudson Strait opening and the northern point of Newfoundland. The uncertainty on the transit times is estimated as \pm 1 month in both 
cases, based on the standard deviation of the velocity components within the composites. Observation-based estimates give compatible results (suggesting approximately 2-4.5 months to transit the northern subregion, and 2.5-5.5 months to reach the southern subregion).

The time scales found above are supported by a lagged correlation analysis between the JFM SIA in the northern subregion [R2] and the SIA of the southern subregion [R3]; the strongest correlation occurs with a lag of two months (i.e. with the MAM mean SIA; $r=0.86$, cf. $r=0.80$ in phase for the raw time series). Ice conditions in the southern subregion [R3] can thus be influenced by the ice conditions in the preceding months in the northern, thermodynamically-driven part [R2]. This link depends, however, on the location of the source of the ice: the southwestern part of the northern subregion, adjacent to the Hudson Strait entrance, is the most plausible source of influence on the southern domain, since anomalies originating further north/northeast would, on average, not be transported sufficiently quickly to influence the conditions further south within the same season. Consistently, this region is also highlighted by regression of the early winter (from OND onwards) SIC on to the JFM SIA of the southern subregion (not shown), and by a lagged regression between the southern subregion and the ice drift velocities of the previous months (Figure SI2b). This lagged regression also suggests that the ice export from the Hudson Strait may potentially play some role in influencing the southern subregion (the region is also highlighted in a lagged regression based on SIC, not shown). The lagged regression on to the northern subregion (Figure SI2a), once more clearly highlights a different region of influence, with the trail of strong explained variance again extending back eastwards along the coast from the subregion [R2] to the region of strong melt/convergence found off the southeast Greenland coast in Figure 2/f [R4 in Figure 3].

\section{Links with atmospheric and oceanic variability}

\subsection{Oceanic conditions during high / low SIA years}

During years where the SIA of the full Labrador Sea region is high, the ocean surface layer in the northern subregion [R2] tends to be notably colder and fresher in the months preceding the ice formation (Figure 7), with the signal becoming strongest from December onwards. This cold, fresh pattern extends back along the coast from the Labrador Sea to the southeast shelf of Greenland, to a region [R4] that is also associated with increased ice velocities (Figure 5b) and melt (Figure 2e;
JFM shown, but strong melt is evident from November onwards in this region) during high SIA years. Regression of the model SSS and SST fields on to the JFM northern subregion SIA time series highlights the strong correlation between the oceanic conditions along the southern coast of Greenland in the preceding months and the sea ice cover in the northern subregion (Figure $8 \mathrm{a} / \mathrm{b})$.

The above along-coast correlation originates (more weakly) in the region [R4] adjacent to the southeast Greenland coast identified above in the preceding autumn (SON, $\sim 45 \%$ variance explained in salinity, $\sim$ $58 \%$ in temperature), suggesting this region as a potential source region in which changes contributing to SIA variability in the following months are forced in the surface waters, and then propagate around the coast. The ocean surface current speeds around this section of the coast are ca. $0.3 \mathrm{~m} \mathrm{~s}^{-1}$ in the model (in agreement with altimetry-based estimates for the region), and thus yield a transit time of just over a month to reach the Labrador Sea, consistent with this hypothesis, given that the distance from the source region [R4] is $\sim 700 \mathrm{~km}$. Further, the melt rate in the hypothesized source region [R4] is strongly correlated with the SIA in the northern subregion [R2] two months later (maximum correlation occurs with NDJ melt, $r=0.92$, Figure 8 black contour region). This thus suggests a scenario in which ice is transported offshore, out of the cold East Greenland Current [R4], where it melts on contact with the warmer waters of the Irminger Current. The Irminger Current system then transports this melt water westward, reaching the northern subregion [R2] a little over one month later, yielding markedly fresh, colder and lighter surface conditions and hence increasing surface stratification (confirmed in composite ocean $\mathrm{T}$ and $\mathrm{S}$ sections taken across the northern subregion using the model data; not shown), promoting sea ice growth in the northern Labrador Sea [R1].

Considering the correlation of the winter salinity in the northern subregion [R2] with that of the preceding months, no significant link is found prior to November, with a notable increase in correlation occurring between November and December. This is thus consistent with the hypothesis of the advection of the signal to the region, as outlined above, and suggests that the signal is not simply a remnant of summer freshening. The sequence of events outlined above is also supported by an analysis of the freshwater input necessary to drive the change in salinity in the northern subregion in the upper quartile of SIA years. The yearly mean freshwater input required between November (the inferred start of the melt influence) and January (the time at which the ice growth is underway) is $\sim 130 \mathrm{~km}^{3}$, consis- 

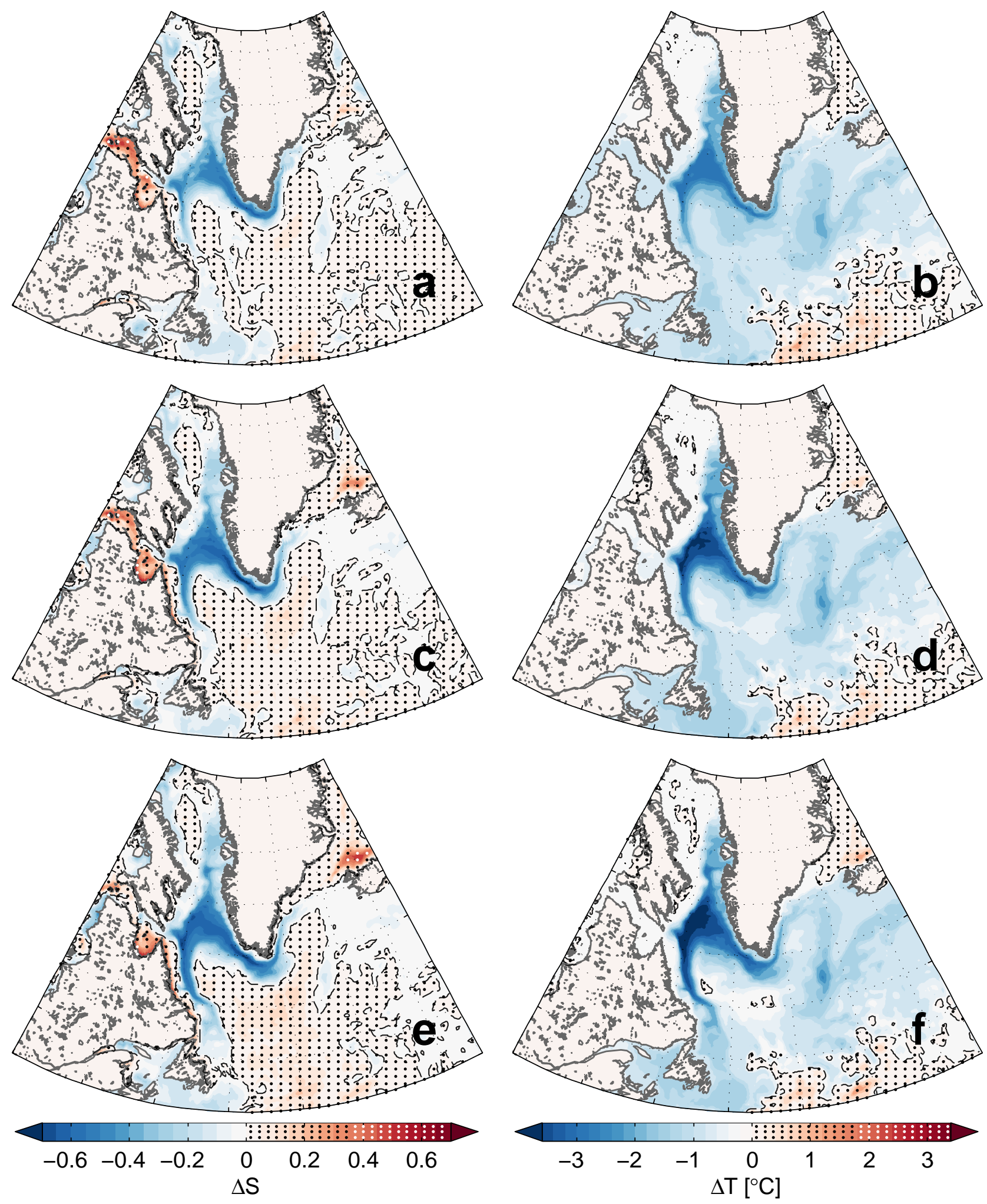

Fig. 7 Difference between high and low SIA composites of (a) NDJ SSS, (b) NDJ SST, (c) DJF SSS, (d) DJF SST, (e) JFM SSS and (f) JFM SST. All quantities are based on model outputs. The composite quartiles are defined based on SIA, and comprise the years listed in Fig. 2. 

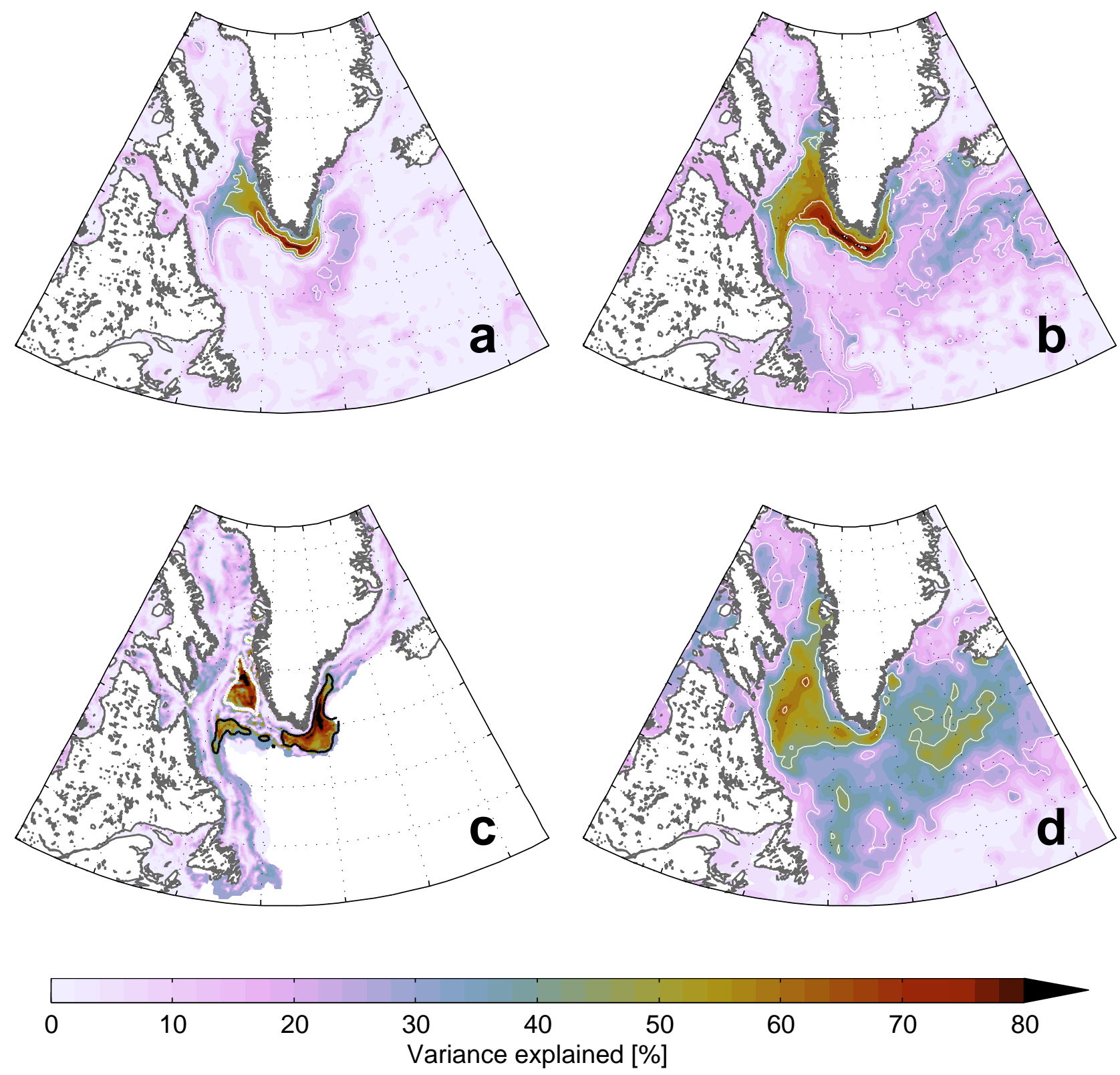

Fig. $8 \%$ of variance explained by regression on to model northern subregion SIA of (a) model NDJ SSS, (b) model NDJ SST (c) model NDJ sea ice production (thick black contours show negatively correlated regions [melt]; thick white contours show positively correlated regions [growth]). (d) Regression on to SSMI northern subregion SIA of DJF OISST.

tent with the mean net meltwater input supplied from the source region over the same period (upper quartile mean input of $\sim 175 \mathrm{~km}^{3}$ over Nov-Dec, with a maximum value of $\sim 460 \mathrm{~km}^{3}$ ) based on the model data. Full details of the calculation are provided in Appendix A. Further, regression of the November-December mean ice production fields on to this time series of required meltwater input again highlights the source region off the southeast Greenland coast [R4], where the net sea ice melt explains $70 \%$ of the variance. Both the corre- lation and budget magnitude analyses thus support the notion that sea ice melt is responsible for the freshening observed.

The results obtained using the model are compared to available observational data to check the consistency of the two. The SST results can be validated using the $1^{\circ}$ OISST data (see section 2), which show the same pattern of co-variability with the northern subregion SIA as was found using the model data (Figure $8 \mathrm{~b} / \mathrm{d}$; note that DJF is shown here, rather than NDJ as in the 
model, since, whilst the pattern is present in NDJ in OISST data set, it is less distinct than in DJF). Whilst validation of the salinity variability is more difficult due to the lack of data availability, the EN4 objective analysis (Good et al, 2013) shows the same patterns of variability over the study period, with two strong episodes of freshening followed by a more saline mean state after approximately 1995 . Further, an analysis of the correlation between the various months again indicates a significant correlation from November onwards with the winter state.

Regression of the model SSS fields on to the JFM SIA of the southern subregion (not shown) yields a pattern which explains significant variance along a narrow region of the ice edge parallel to the Labrador coast both in phase and (weakly) with one month lag. At one month lag (i.e. with SSS leading), the correlated region also adjoins the pattern obtained in the northern subregion regression, but with much weaker correlations ( $\sim 45 \%$ variance explained; cf. $\sim 87 \%$ variance explained in SSS in the equivalent analysis performed for the northern region at this lag). No significant correlations are found at earlier lags. This hence does not suggest the surface stratification to be a primary control on the southern region SIA.

\subsection{Atmospheric conditions during high / low SIA} years

It was hypothesized above that the increased SIA in the northern subregion [R2] is associated with enhanced ice melt off the southeast Greenland coast [R4]. Composites of $10 \mathrm{~m}$ wind associated with high and low ice conditions for the full regior ${ }^{2}$ suggest that high ice conditions are associated with strong westerly winds across the Labrador and Irminger Sea during the preceding months (between 0 and 3 months before the event), with these winds having a northwesterly orientation along the southwest coast of Greenland and southwesterly to the east of Greenland (Figure 9a). A low pressure centre can be noted in the region of Ammassalik (black diamond in Figure 9a), around which the winds circulate. Regression analyses (not shown) show that the northern subregion SIA is well correlated with the $10 \mathrm{~m}$ wind in the region across the southern part of Greenland and along its southern coast between November

\footnotetext{
2 Note that whilst high and low SIA quartile years corresponding to the full Labrador Sea region are used throughout in the construction of the composites, the years representing the upper and lower SIA quartiles are, with the exception of one year in both quartiles, the same as for the northern subregion and yield essentially identical results.
}

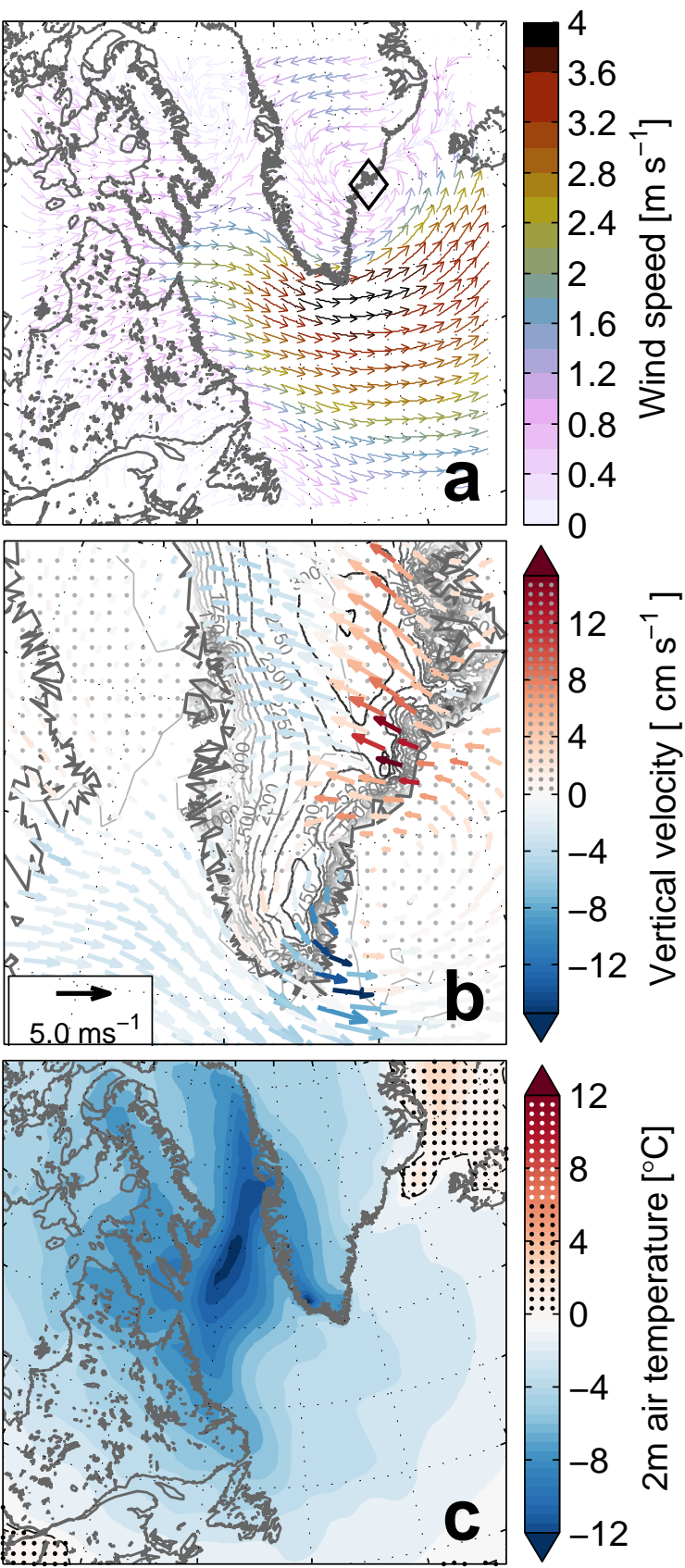

Fig. 9 (a) Difference between NDJF ERAi 10m wind composites for high minus low JFM SIA states. The composite quartiles comprise the years listed in Fig. 2. The black diamond marks the position of Ammassalik, referred to in the main text. (b) Difference between NDJF ERAi wind composites for high minus low SIA states where wind is averaged over 0-2700 m altitude. Arrow size indicates the horizontal component of the wind anomaly (scaled relative to reference arrow in bottom left corner), whilst colour indicates the vertical anomaly, where negative values indicate downward anomalies. The surface elevation of the Greenland ice sheet (Bamber et al 2001) is shown by the grey contours, labelled in $\mathrm{m}$. (c) Difference between DJF $2 \mathrm{~m}$ air temperature composites for high minus low SIA states. 
and March. Along the southwestern coast and southern tip of Greenland, the wind anomalies, following the coastline, are oriented so as to favour an offshore Ekman transport; this is indeed confirmed in the ocean current anomalies in the model (not shown), which suggest an enhanced southwards transport in the surface layers along the southern tip of Greenland.

Motivated by the potential link with the oceanic subpolar gyre, the wind stress curl has also been analysed; however, the analysis (not shown) reveals only localised regions of correlation with the Labrador Sea ice area, highlighting the changes in wind orientation over the central Labrador Sea region (approx $59-62^{\circ} \mathrm{N}$, $60-54^{\circ} \mathrm{W}$ ) during high ice years, and a dipole pattern of wind stress over the Irminger Sea. It has not been possible to make any conclusive link with the strength of the oceanic gyre in the analyses performed here.

Since the topography of Greenland varies steeply over relatively small horizontal distances, the wind field at higher altitudes is also examined (again using ERAi). Again taking the difference between the high and low SIA year composites, whilst the broad scale pattern of the horizontal flow remains the same as the $10 \mathrm{~m}$ composites, years with high SIA are associated with strongly enhanced downslope winds down the steepest part of the southeastern coastline (Figure 9p, averaged over $0-2700 \mathrm{~m}$, i.e. the height of the southern slope, but the pattern shows little dependence on the precise choice of levels). The vertical velocities here are most strongly correlated with the JFM SIA in late autumn ( $52 \%$ variance explained in NDJ).

Consistently with the enhanced downslope winds, the high/low SIA year composite differences are associated with a distinct signature in geopotential height ca. $500 \mathrm{hPa}$, with a strong negative anomaly over the east Greenland coast. The pattern is approximately barotropic, and the centre of the system is again aligned with the Greenland topography (Figure 102). This NDJF pattern co-varies with the JFM northern subregion SIA [R2], explaining approximately $60 \%$ of local variance (Figure 10p). Repeating the regression analysis for the southern subregion [R3], the SIA of this region is found to be well correlated with the geopotential height at $500 \mathrm{hPa}$ on the western side of Greenland (Figure 10 in contrast with the co-variability with the eastern side found for the northern subregion. This northern subregion / east of Greenland and southern subregion / west of Greenland separation is found at all heights examined in this analysis (1000-200 hPa), and suggests two separate driving mechanisms for the two subregions.

$2 \mathrm{~m}$ air temperature anomalies (Figure 9k) evolve in the same manner as those of the SST (Figure 7d), with the strongest (cold) air temperature anomalies in the
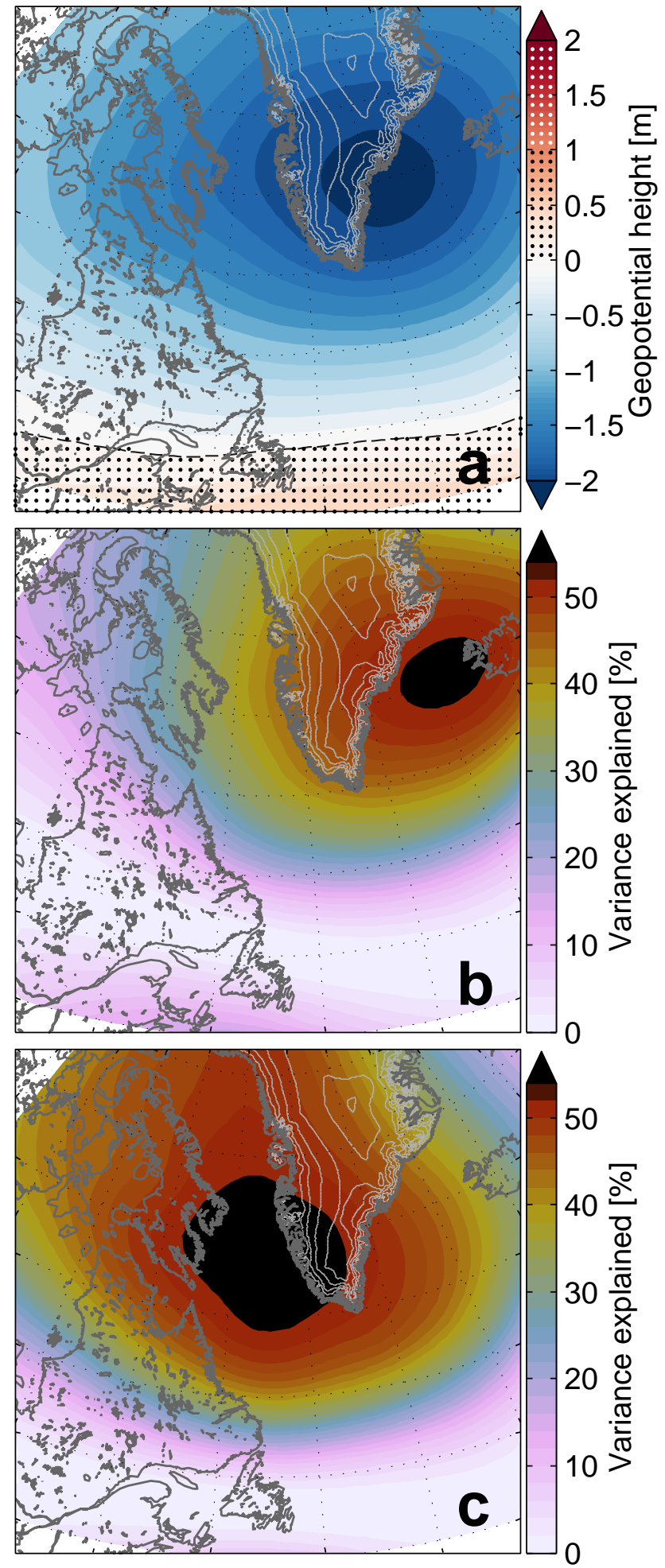

Fig. 10 (a) Difference between NDJ ERAi $500 \mathrm{hPa}$ geopotential height composites for high minus low SIA states. The composite quartiles comprise the years listed in Fig. 2. (b) \% of variance explained by regression of SIA in northern subregion on to NDJ $500 \mathrm{hPa}$ geopotential height. (c) \% of variance explained by regression of SIA in southern subregion on to NDJ $500 \mathrm{hPa}$ geopotential height. Thin light grey contours show the surface elevation of the Greenland ice sheet for reference, as in Figure 9 
high minus low SIA composite occurring over the ice edge, in the region of strongest SIC anomalies (cf. Figure 1p). At monthly temporal resolution, the anomalies are formed in phase with those of the ice and SST; the strong spatial localisation of the largest negative anomalies along the ice edge suggest that these maxima occur as a response to the presence of ice, rather than being the cause of the ice formation. However, this does not discount a potential earlier influence of cold air temperatures in initiating the ice growth that leads to the later negative anomaly maxima in air temperature, particularly since these anomalies overlie the region of positive production identified in Figure 2 $\mathrm{c} / \mathrm{e}$, and are associated with northwesterly wind anomalies (Figure 9), that would tend to advect cold air from the Canadian Arctic Archipelago region.

\section{Longer-term context}

The data sources analysed above cover a 35 year period. Because the record length is comparatively short relative to the time scales of variability (e.g. Figure 1 we conclude the analysis by examining two longer data sources to explore whether recent variability is characteristic of the longer-term behaviour. We thus analyse data from the ERA20C reanalysis, over 1953-2010, permitting the addition of approximately 20 years within a realistic context, and output from a CMIP5 coupled model (see section 2 for details of both sources), which we do not expect to accurately reproduce the observed record, but nevertheless permits an assessment of the relevance of the mechanisms described above in an independent context. We emphasize again that our intention here is not to perform a model comparison, but simply to place the consistent results obtained from the available observations and the forced ocean-sea ice model run in a wider context.

Using the ERA20C data, very similar results are obtained to those previously found using SSMI / ERAi (Figure SI3). The northern subregion is defined using the criteria previously identified from the model / SSMI data (the southern subregion again being defined as the difference between the full Labrador Sea region and the northern subregion), and the SIA time series obtained explain variability over coherent regions that correspond well to those obtained using SSMI (cf. Figure SI3a/b and Figure SI1b/c). Consistent patterns are also obtained in both the heat flux (Figure SI3d; note that this was not previously shown for SSMI or the ice-ocean model) and wind (Figure SI3e) regressions, suggesting that the conditions associated with high / low SIA states during the post-1979 period also hold during the earlier record (confirmed by a further analysis restricted only to the $1953-1978$ period). However, the pre-1979 ERA20C total region SIA record (Figure SI3c) is characterised by a relatively stable period between 1953-1969, followed by a multiannual event, covering approximately 1969-1977, over which the SIA is enhanced. The addition of this earlier part of the record thus adds another multi-annual event to the two events occuring between 1979 and 1995 noted in the preceding analysis; however, this does not clarify whether these events are atypical oscillations around a stable baseline state, or whether the longer-term variability is characterised by such multi-annual cycles. We thus draw on the coupled model output from MIROC4h to attempt to place this variability in a temporal context.

The analyses performed above using observational and the coupled ice-ocean model data were repeated using the MIROC4h outputs (shown in Figure SI4 for some variables). The mean states and the regions in which the northern and southern subregion SIA time series explain variance (not shown) generally correspond well to those shown for SSMI and the ice-ocean model, although, as for the ice-ocean model, the southern pole noted adjacent to Newfoundland in the SSMI data is not well reproduced, with the ice cover at the southern extent of the region being weaker than observed on average. On regression of the atmospheric and oceanic fields investigated above on to the northern subregion, the same spatial patterns of covariance are revealed as in the previous analysis, suggesting that the mechanisms identified above also contribute to driving Labrador Sea ice variability. In particular, significant correlation is found with the meltwater flux due to sea ice thermodynamics off the south east coast of Greenland in the preceding NDJ (Figure SI4b), and a trail of positive correlation extends around the southern Greenland coast in the $1 \mathrm{~m}$ depth salinity term ${ }^{3}$ (Figure SI4a). Localised correlation between the SIA in the northern subregion and the geopotential height at $500 \mathrm{hPa}$ over the preceding DJF is again also found (Figure SI4c), with the correlation pattern being aligned with the Greenland topography, as previously (cf. Figure 10p). Lagged regressions of the preceding months' SIC on to the JFM northern and southern subregion SIA (not shown) reveal the same spatial evolution as in Figure SI1. In brief, the similarity between the mechanisms associated with high ice coverage appears to be sufficiently similar to permit comparison between the periodicity of the variability found in the MIROC4h SIA and that analysed using the observations and a realistic ice-ocean model above.

3 note that SSS is not available for MIROC4h in the CMIP5 archive, hence the use of the $1 \mathrm{~m}$ depth level 
Spectral analyses (not shown) of the SIA time series for both the full region Labrador Sea SIA and the northern subregion SIA show an enhancement in power over the 4-8 year period range. This emerges as a region of higher power, rather than one specific peak, suggesting that this does not represent a single characteristic time scale of oscillation, but rather implies that the variability within the models is frequently characterised by episodes of multiannual variability with time scales in the 4-8 year range (cf. SIA time series shown in Figure SI4d). Within this context, the multiannual SIA variability described by the SSMI and ice-ocean model output does not appear to be atypical. However, ultimately longer observational time series will be necessary to clarify this question.

\section{Discussion}

\subsection{Proposed mechanism of variability}

The observational data, forced ocean-ice model simulation and the CMIP5-class model analysed all suggest a coherent set of processes that determine the inter- to multiannual sea ice cover variability in the Labrador Sea (synthesized in schematic form in Figure 11). In years with high winter ice cover, between November and January, anomalously strong (north)westerly winds blow over the Labrador Sea and the southeast coast of Greenland. The strong downslope winds along the southeastern Greenland coast drive sea ice offshore [R4], out of the cold East Greenland Current, where it melts on contact with the warmer underlying ocean. This freshwater is advected with the subpolar gyre circulation towards the northern Labrador Sea, where it arrives one month later, and contributes to enhancement of the surface stratification of the ocean, isolating the surface from the underlying oceanic heat [R2]. The region is cooled by the atmosphere, and sea ice grows, with the strongest growth rates occurring adjacent to the existing sea ice edge [R1]. This newly-formed ice is exported southwestward out of the region, where, depending on the localisation of the initial formation region, it may contribute to the variability of the more southerly Labrador coast region ice cover [R3] within the same winter. As before, sea ice that is driven offshore during this process melts on contact with the surface water.

The sequence of mechanisms outlined above is rather consistent with many of the previous ideas outlined in the literature, which have suggested an important role of westerly winds, which in turn modulate surface air temperature (Ikeda et al, 1988, Mysak et al, 1996, Deser et al, 2002, Peterson et al, 2015) as a key influence on regional sea ice variability. Nevertheless, the results presented above suggest that the ocean surface state also plays a primary role in determining the inter-/multiannual variability, with enhanced stratification of the ocean surface layers, associated with anomalously low salinity, permitting the strongest ice coverage. Again, this is consistent with the previous findings of Mysak and Manak (1989); Mysak et al (1990); Slonosky et al (1997); Marsden et al (1991), who have all suggested that stable ocean stratification can enhance ice formation in the region. Whilst our results are consistent with the finding of Fenty and Heimbach (2013) that freshwater promotes efficient advancement of the ice edge, in this work we suggest that there is a significant freshwater contribution, originating to the southeast of Greenland, that is propagated to the region, and that is necessary to sufficiently enhance the surface stratification to achieve high ice states. This does not preclude a further influence of freshwater from ice that melts in place, as suggested by these authors; however, we hypothesize that this influence is not the primary driver of the inter- to multi-annual scale variability addressed here. The southward export of ice anomalies originating in the north of the region, previously suggested by Ikeda et al (1988), is confirmed by our results; nevertheless, we suggest that the relative importance of this influence on the southern subregion is strongly dependent on the region of initial ice formation (section 3.2. Ice formed in the northern subregion is thus not guaranteed to be transported sufficiently far within a single season to reach the southern subregion and, consequently, our results indicate two regions of distinct variability (i.e. the northern and southern Labrador Sea) that may nevertheless co-vary, particularly in high ice states. Such states being intermittent and often characterised by a multiyear persistence, the connection between the two regions is thus strongest in the low-frequency range.

The 4-8 year cycles that appear to be typical of the variability in the coupled model (and that are also reproduced in the temporally-limited SSMI and ice-ocean model time series) suggest a certain persistence, indicating a potential role of the ocean as the memory of the system. Evaluation of the mean deseasonalised SST/SSS over the northern subregion in the ocean-ice model (not shown) confirms that both quantities also exhibit the low-frequency variability found in the winter SIC, with the cool/fresh anomalies persisting even into summer, indicating that a strong initial cold/fresh state may persist for a sufficiently long period to precondition the following winter, favouring the formation of further high ice anomalies at that time. Further, this process may be repeated over several years, according 


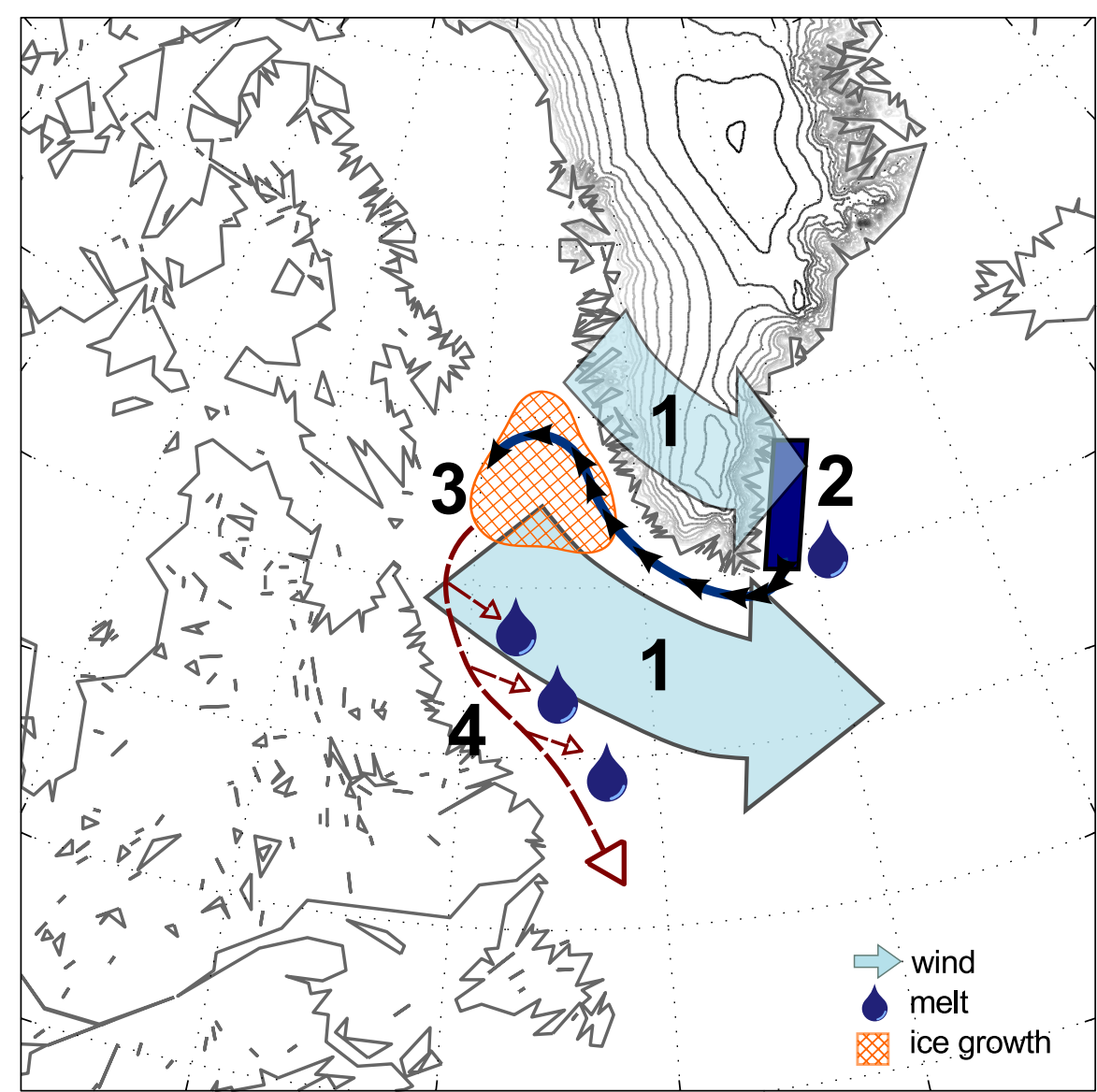

1. Nov-Jan: enhanced westerly winds over Labrador Sea and Greenland. Katabatic winds descend down SE slope of Greenland.

\section{Nov-Dec: sea ice is pushed offshore by winds and melts. Subpolar Gyre circulation transports fresh water westwards to Labrador Sea}

\section{Jan-Mar: surface of Labrador Sea is strongly stratified. Sea ice grows.}

4. Jan-Mar: sea ice is
advected out of the
growth region along
the Labrador
coastline. At the outer
ice edge, ice melts on
contact with warmer
surface waters.

Fig. 11 Schematic of processes leading to enhanced Labrador Sea ice cover.

to the time / exterior forcing necessary to erode this enhanced stratification. Whilst here we report modelbased quantities, comparable low-frequency variability can also be noted in observational data (see, e.g. the Ocean Weather Ship Bravo data reported in Häkkinen (2002), their Figure 1), suggesting that the behaviour reproduced by the model is plausible.

Some potential influences on Labrador Sea hydrography are not included in the ocean-sea ice model from which we deduce the schematic of variability outlined above: notably, neither glacial melt from the Greenland ice sheet nor icebergs are represented. These potential influences, however, should be present in the observational data used here, and we thus briefly attempt to evaluate their contributions. Considering first glacial melt, Bamber et al (2012), detailing increased freshwater fluxes into the North Atlantic from Greenland since the 1960s, provide an estimate of the glacial meltwater supplied to the Labrador Sea. Drawing on their Figure SI1, the reported difference between highest and lowest meltwater fluxes over the 1979-1998 period is approximately $40 \mathrm{~km}^{3} / \mathrm{yr}$. Through application of the equation of conservation of salt (detailed in Appendix A), this value can be used to estimate the potential influence of such an input on the salinity of the region (Appendix B). The salinity change obtained is one order of magnitude smaller than those found during the large freshening events in both the model and EN4. Further, the estimates of glacial melt suggest a dramatic increase in freshwater input from the late 1990s onwards; this is incompatible with EN4, which shows the same salinity variability as the model, suggesting a more saline state from the mid-1990s onwards. Based on the discordance in both the patterns of variability and the magnitude of the inputs, we suggest that it is unlikely that this glacial meltwater has played an important role in determining the hydrographic variability of the region analysed here (Appendix B). The potential role of iceberg melt is more difficult to estimate given the lack of observational data. However, we note, as for the glacial meltwater, the disparity between the increased melt that might be anticipated to occur following the switch to a positive Atlantic Multidecadal Oscillation (AMO) state in the mid-1990s (e.g. Straneo and Heimbach, 2013) and the apparently more saline state that is found in the study region after this time, both in the 


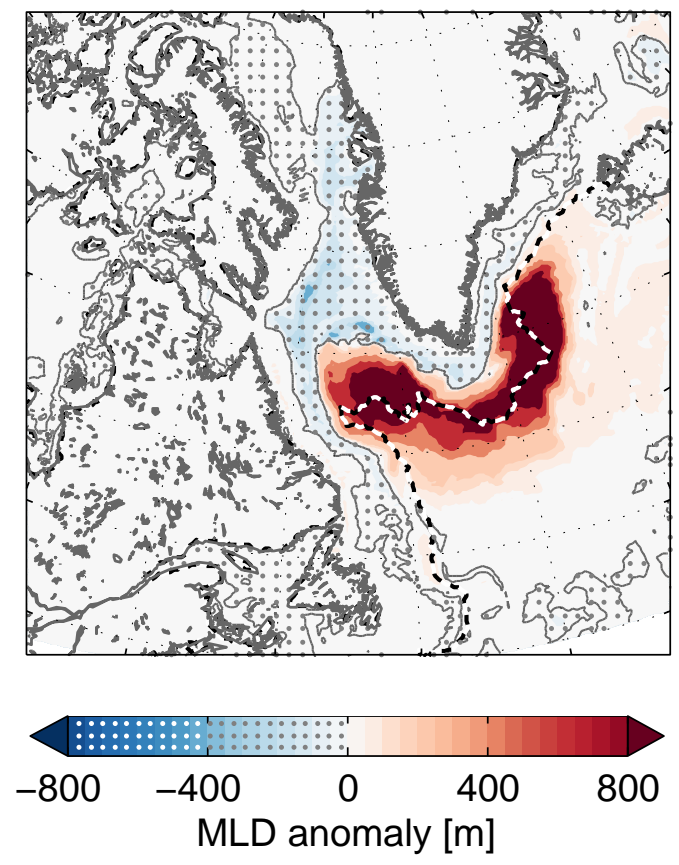

Fig. 12 Difference between mixed layer depth composites composed of highest minus lowest quartile Labrador Sea SIA years (defined in Fig. 2). Black and white dashed line shows maximum ice cover.

model and in EN4. We thus conclude that the lack of representation of these processes in the model is unlikely to have a critical influence on the simulation of the hydrography of the region analysed here over the study period.

\subsection{Implications for deep convection in the Labrador} Sea

As noted previously, high sea ice cover in the Labrador Sea is associated with strengthened (north)westerly winds across the region, and cool, fresh sea surface anomalies in the Labrador Sea and along the southern Greenland coastline. The implications for the oceanic mixed layer depth are thus not trivial to disentangle: whilst the enhanced wind stress would promote deepening of the mixed layer, destabilising the upper water column, the increased freshwater input to the upper ocean that permits the sea ice production in the region would tend to act in the opposite sense, with the enhanced stratification stabilising the upper water column, and being associated with shoaling of the mixed layer. The difference between the highest and lowest Labrador Sea SIA quartile composites of ocean mixed layer depth (MLD) using output from the ocean-ice model (with the MLD being determined using a density criterion based on a difference of $0.01 \mathrm{~kg} \mathrm{~m}^{-3}$ relative to the density at $10 \mathrm{~m}$ ) is shown in Figure 12 . The values of MLD given by the model are most likely too extreme, particularly in regions of deep convection, owing to the sensitivity to the stratification of the full water column, which is difficult to reproduce. For this reason, here we simply focus on interpreting the pattern of the anomalies produced, which confirms the competing influences of the two responses outlined above, with a shoaling of the mixed layer in the northern part of the domain during years with strong ice cover, and a deepening of the mixed layer outside the ice covered region along the path of the strongest wind stress anomalies (cf. Figure 9), associated with strongly enhanced heat flux (shown for ERA20C in Figure SI3d; other data sources show the same pattern). The shoaling, rather than deepening tendency in the sea ice covered region confirms the dominant effect of salinity over temperature anomalies in controlling the density anomalies during these high ice events. This dipole of mixed layer depth anomaly appears from the preceding November onwards, with a pattern consistent with a reduction of the MLD along the hypothesized path of meltwater advection from the southeast coast of Greenland and along the ice edge. In the model, the deep convection in the Irminger Sea occurs from November onwards, whilst that in the Labrador Sea appears later, between January and March.

The climatological position of deep Labrador Sea convection (e.g. Pickart et al, 2002, Våge et al, 2009a Yashayaev and Loder, 2016) lies, broadly, within the region $50-55^{\circ} \mathrm{W}, 55-60^{\circ} \mathrm{N}$. Comparing with the model ice budget composites, this region experiences no contribution from the ice budget during low ice years, but does receive some meltwater input during high ice years (cf. Figure $2 \mathrm{a} / \mathrm{c} / \mathrm{e}$, for example), which could act to stabilise the upper water column and inhibit mixed layer deepening. Examining the correlation between the Labrador Sea SIA and the model MLD (not shown), strong positive correlation ( $80 \%$ variance explained) is found along the band of strong positive mixed layer anomalies of Figure 12 in a region of weak mean sea ice cover that corresponds to an area of advection/melt according to the sea ice volume budget of Figure 2. We hypothesize that this arises as a result of the westerly wind forcing (and associated enhanced heat fluxes) associated with the high sea ice conditions, as the increased sea ice melt here during high ice years should act in the opposite sense, promoting rather a shoaling of the MLD. The fact that the MLD dipole of shallower / deeper mixed layer depth remains stable throughout the winter season further suggests that the influence of brine rejection 
associated with sea ice formation does not play a significant role in changing surface properties, at least in the model.

\subsection{Links to larger-scale climatic variability}

As outlined above (e.g. Figure 11), the sequence of mechanisms associated with high ice conditions in the Labrador Sea appears to be initiated by strong westerly winds blowing across the region. Many studies have previously linked the variability of the Labrador Sea ice cover to the NAO (Rogers and van Loon, 1979, Walsh and Johnson, 1979; Fang and Wallace, 1994; Mysak et al, 1996; Prinsenberg et al, 1997; Deser et al, 2000, amongst others), which is also generally associated with the presence of strong westerly winds across the region. Furthermore, it has also been proposed that the Labrador Sea ice cover may impact the state of the NAO (Kvamst $\varnothing$ et al, 2004; Seierstad and Bader, 2008; Strong et al, 2009), with high ice states inducing a negative NAO and vice versa. Nevertheless, other studies have stressed that the NAO is not sufficient in itself to fully explain local climatic variability (e.g. Våge et al, 2008, 2009a, Moore et al, 2013), or have combined the NAO index with other climatic metrics to improve correlation (e.g. Wang et al, 1994, Peterson et al, 2015).

With the aim of clarifying links to larger-scale climatic variability, particularly the NAO, the correlation between the Labrador Sea SIA time series and the NAO index is calculated. Taking into account previous authors' suggestions that this may not be the optimal predictor of Labrador Sea ice conditions, we also consider other relevant indices, namely the Greenland Blocking Index (GBI; Fang, 2012, Hanna et al, 2016) and the AMO. The inclusion of the GBI is motivated by the significant correlation found in this work between the Labrador Sea SIA and the geopotential height over Greenland (often used as a metric of Greenland blocking; here we use the Hanna et al (2013) definition, based on this quantity), the strong correlation between the GBI and NAO (e.g. Hanna et al, 2016) and previous suggestions in the literature that Greenland blocking plays a key role both in describing and modulating the NAO (Davini et al, 2012b). The strong correlation between the GBI and the NAO is due in part to their representation of common processes, with both measures inherently providing a metric of the strength of the zonal atmospheric flow over the Atlantic (e.g. Woollings et al, 2008). High GBI states are associated with a southward displacement of the jet stream (e.g. Woollings et al, 2010; Davini et al, 2012a), and thus generally with circulation patterns analogous to the negative phase of the NAO; differences between the two measures and their appropriateness as predictors here will be discussed further below. However, because of the common physical processes involved and the strong correlation (thus multicollinearity) between these two indices, no attempt will be made to examine the combined skill of these two metrics in the following analyses. The inclusion of the AMO is motivated by the previous suggestion of Peterson et al (2015) that the combination of this index with the NAO leads to improved correlation of sea ice conditions along the Canadian east coast and by the fact that, the AMO being defined based on SST, large-scale oceanic temperature might reasonably be expected to exert some influence on local ocean temperatures, and hence potentially on sea ice.

Correlations between the JFM Labrador Sea SIA time series, the DJF NAO and GBI and the preceding ASO AMO indices (corresponding to the times at which the correlations are strongest individually), and combinations of these indices, are given in Table 1 for all data sets (equivalent indices are re-calculated from the model variables for MIROC4h). Consistent results are obtained among all three data sets, with the GBI being consistently better correlated than the NAO (this difference is significant at the $95 \%$ level for all data sets apart from MIROC4h), and the strongest correlations being obtained by combining the GBI and AMO indices. High NAO and low GBI (i.e. less blocking) thus correspond to higher SIA states in the Labrador Sea. The AMO is strongly characterised by low-frequency variability; it is for this reason that, although the index is highly correlated with the Labrador Sea SIA, the correlations are not significant. Nevertheless, the notion that modulation of the surface temperature should affect sea ice formation appears logical, and it is encouraging that a significant role is also found in MIROC4h, which is independent of the observation-based data. We thus hypothesize that the AMO may exert a second control on Labrador Sea SIA on multidecadal time scales, in addition to the freshwater-based control outlined above, that acts on inter- to multiannual time scales. At multiannual time scales, cross wavelet analyses between the Labrador Sea SIA and NAO/GBI (not shown) confirm that the strongest covariance occurs at frequencies corresponding approximately to 4-8 year periods, consistent with the periodicity of the sea ice in this range noted previously, and also with the enhanced power in the ca. 8 year period range noted in both the NAO and GBI time series by Hanna et al (2016). Overall, then, the combined GBI/AMO indices appear to provide the best predictor of Labrador Sea SIA; however, the NAO/AMO combination also performs well, and the correlations obtained are (most notably in the 
Table 1 Correlations between JFM Labrador Sea SIA calculated for SSMI, the ice-ocean model, ERA20C and MIROC4h and combinations of NAO (DJF mean), GBI (DJF mean) and AMO (ASO mean) indices. Values that are significant at the $95 \%$ level are given in bold.

\begin{tabular}{llllll}
\hline & NAO & GBI & AMO & GBI/AMO & NAO/AMO \\
\hline SSMI & $\mathbf{0 . 4 9}$ & $\mathbf{- 0 . 7 6}$ & -0.71 & $\mathbf{0 . 8 7}$ & 0.79 \\
Ice-ocean model & $\mathbf{0 . 5 5}$ & $\mathbf{- 0 . 7 7}$ & -0.60 & $\mathbf{0 . 8 5}$ & 0.78 \\
ERA20C & $\mathbf{0 . 4 4}$ & $\mathbf{- 0 . 6 9}$ & -0.58 & $\mathbf{0 . 8 2}$ & $\mathbf{0 . 7 2}$ \\
MIROC4h & $\mathbf{0 . 5 7}$ & $\mathbf{- 0 . 6 6}$ & -0.57 & $\mathbf{0 . 7 9}$ & $\mathbf{0 . 7 7}$
\end{tabular}

MIROC data) not greatly different from the GBI-based combination.

Many of the features outlined in the atmospheric and oceanic fields during high ice events are consistent with the presence of westerly Greenland tip jets (e.g. Doyle and Shapiro, 1999, Pickart et al, 2003, Våge et al, 2008, 2009b), being associated with very intense, localised, topographically-steered winds, a dipole pattern in the wind stress curl (identified during our analysis, but not shown in this work) and deep convection in the Irminger Sea, as identified in the composites analysed here (Figure 12). The peaks in Labrador Sea SIA shown in Figures $1 \mathrm{k} / \mathrm{f}$ further correspond to winters with an elevated frequency of tip jet events in the analysis of Våge et al (2009a) (their Fig. 4). Moore (2003) found tip jet occurrence to be linked to the interaction of synopticscale cyclones with the topography of Greenland, and this is thus consistent with the effects of Greenland blocking, where, during blocked states, migratory cyclones would be diverted away from the region (e.g. Rex, 1950) and the jet stream diverted southwards (e.g. Woollings et al, 2010, Davini et al, 2012a).

We find in this work that the Labrador Sea ice area variability is significantly better correlated with the GBI than the NAO (as individual predictors). This is coherent with the notion that the ice export off the southeast Greenland coast is linked to tip jet activity, and that the GBI provides a representative metric of the latter. Previous studies have highlighted good correlation between tip jet occurrence and both the NAO and also the position of the Icelandic Low (Bakalian et al, 2007, Våge et al, 2009b), whilst Davini et al (2012b) further report that the location of the Icelandic Low varies with Greenland blocking. Our result that the GBI is better correlated is thus again consistent within this framework, where not only the intensity of the Icelandic Low, but also its location appears to be important in determining tip jet occurrence. Further support for the greater role of Greenland blocking in modulating the sea ice cover can be found through comparison of the composite wind field associated with high NAO years (not shown) with that associated with high SIA years. On taking the difference between the two, notable differences are found, particularly in the Denmark Strait region, where the strong barrier wind signal is evident in strong NAO years (e.g. Moore and Renfrew, 2005), but absent in the high SIA composite (also suggesting that there is no particular influence of the barrier wind flow regime on the occurrence of high Labrador Sea ice cover). We thus suggest that the weaker correlation with the NAO, which, by its very definition, describes much larger-scale variability, may arise from the insufficiency of this index to describe both the strength and the orientation of the small-scale local flow, where, for the Icelandic Low, the NAO describes primarily the intensity of the cyclone (Davini et al, 2012b). This apparent physical consistency might be taken as further motivation to prefer the GBI/AMO combination discussed above to the $\mathrm{NAO} / \mathrm{AMO}$ as a predictor of SIA variability, aside from the moderate increase in skill.

Regarding the potential for advance predictability of the interannual variability of the winter sea ice cover, based on our analyses, we suggest that the single greatest contributor to skill in this respect would be Greenland blocking, were it possible to predict this accurately in advance; accomplishment of this feat would, however, be unlikely to be trivial (Barnes, 2013; Screen et al, 2014, Cohen et al, 2014, Barnes et al, 2014). At longer time scales, our results suggest that the AMO may potentially provide some predictability; however, given the low-frequencies involved, this should be studied with time series longer than those available here.

Slightly north of the tip jet region, Oltmanns et al 2014, 2015) noted an important role of short-lived, highly localised strong downslope wind events in the valley of Ammassalik in determining the local climate, and found implications for the wider region (including, for example, convection in the Irminger Sea). The patterns observed in that work are clearly distinct from the wind patterns noted here; however, Oltmanns et al (2014) show that these short-lived events have a remarkable influence on the local sea ice cover, and are capable of rapidly advecting sea ice offshore, thus clearing the local area of ice during a matter of days. A full investigation of the small-scale contributions (spatially and temporally) in initiating the offshore ice export and thus melt that is hypothesized to trigger the cycle outlined in Figure 11 lies outside the scope of this work; 
however, even if it is possible to achieve a high level of skill in describing the Labrador Sea SIA using largescale, monthly metrics (i.e. the combined GBI/AMO indices outlined above), based on the consistency of the above studies with the results found here, we suggest that it is very plausible that small-scale and temporally short-lived processes are ultimately at the foundation of the sequence.

Finally, we consider the potential link between freshwater and/or sea ice originating in the Arctic and transported through Fram Strait and the sea ice variability in the Labrador Sea ("freshwater flux" is used here to describe the liquid freshwater component, and "sea ice flux" to describe the solid freshwater). Since our analyses suggest a significant role of upper ocean stratification in modulating the regional sea ice, and since the presence of sea ice along the eastern Greenland coast is a necessary prerequisite to initiate melt, increased freshwater/ice flux from further north could potentially play a role in the cycle (e.g. Yang et al, 2016 Boning et al 2016). Using the ocean-ice model, it is possible to calculate the freshwater and ice fluxes through the Fram and Denmark Straits. A correlation of $r=0.58(r=0.68)$ is found between the ice flux through the Denmark Strait in the preceding October and the Labrador Sea (northern subregion) SIA; in particular, the high ice events in 1983 and 1990 are preceded by increased ice flux through the strait. At the Fram Strait, a correlation of $r=0.57(r=0.62)$ is further found with the ice flux of the previous August (no significant correlation is found with the freshwater flux through either strait). On including the October ice flux through the Denmark Strait as a further predictor in the AMO/GBI multiple linear regression considered above, the correlation with the Labrador Sea SIA increases to $r=0.91$ (or $r=0.85$ for the AMO/NAO combination; the combined AMO/GBI/ice flux estimator is shown alongside the original SIA time series in Figure 13 for both the ice-ocean model and MIROC4h output). As proposed by, e.g. Aagaard and Carmack (1989); Häkkinen (1993); Goosse et al (2002), this suggests that Arctic ice export can also contribute to determining lower-latitude conditions.

The lack of significant correlation with the freshwater flux through either the Fram or Denmark Strait is in agreement with the lagged analyses of salinity performed above (Figures 7, 8 and SI4), where the correlation between the Labrador Sea SIA and preceding months' salinity is limited to the southern part of the southeast Greenland coast, approximately south of Ammassalik (ca. $65.6^{\circ} \mathrm{N}$ ). Previous studies have suggested that the ice and/or freshwater transport through Fram Strait may play a key role in initiating North Atlantic freshening, notably in connection with the Great Salinity Anomalies of previous decades (Walsh and Chapman, 1990, Häkkinen, 1993, Belkin et al, 1998, Karcher et al, 2005). Our analyses suggest that local wind conditions along the southeast coast of Greenland, described here by the GBI, are also a key component in determining the quantity of meltwater supplied to the Labrador Sea. We thus find localised generation of melt off the southeast Greenland coast to play the strongest influence in setting Labrador Sea winter ice-ocean properties, with the link with the Arctic conditions being determined predominantly by the ice export (which shows a weaker correlation).

\section{Summary and conclusions}

Based on consistent results identified using observational data, an ocean-ice model forced with ERAi atmospheric reanalysis, the ERA20C reanalysis and output from a fully-coupled CMIP5 model (MIROC4h), we find that the sea ice cover of the Labrador Sea is controlled on inter- to multiannual time scales by a sequence of events initiated by strong westerly winds over the region. Sea ice is thus advected offshore along the southeast Greenland coast, driven out of the East Greenland Current and melts on contact with the warmer waters to the east, leading to the transport of anomalously fresh water westwards in the Irminger Current system. The arrival of this fresh water in the Labrador Sea increases the surface stratification and permits enhanced sea ice production. This sea ice is removed from the region by advection, and transported southwards along the Labrador coast. It is possible for the ice advected southwards from the Labrador Sea to travel sufficiently far south to influence the variability along the southern Labrador coast / Newfoundland within the same winter; however, in order for this to occur, the ice production must be sufficiently far south for the ice to have time to reach the southern region before the annual retreat. There is thus not a consistent link between the variability of the Labrador Sea region (which experiences an important thermodynamic contribution to its variability) and the Labrador coast / Newfoundland region (where the variability is mechanically-driven, and may also experience some influence from the ice export from Hudson Strait).

A 4-8 year cyclicity appears to be associated with the sea ice variability. Similar periodocity has also been found in the GBI and NAO indices, and it is hypothesized that this may potentially indicate feedbacks between the Labrador Sea SIA and the atmosphere. On multidecadal time scales, the presently available data appear to indicate a link with the AMO, suggesting 

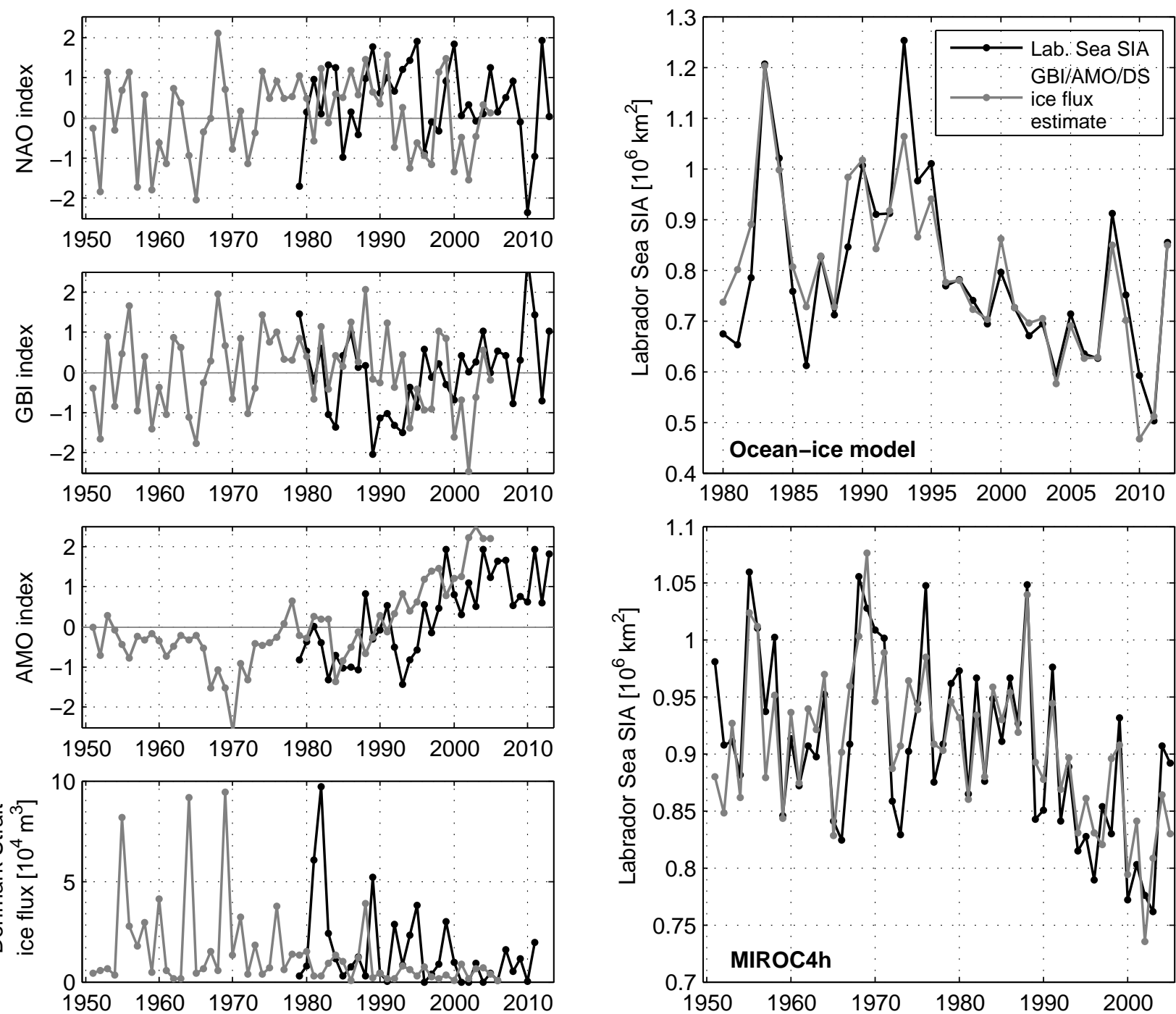

Fig. 13 LH column, from top downwards: normalized NAO, GBI and AMO indices from observational data (dark colours) and MIROC4h equivalent (light colours); bottom LH panel shown the sea ice flux through Denmark Strait (lighter colour shows MIROC4h; darker colour shows the coupled ocean-ice model). RH column, top: Labrador Sea SIA from coupled ocean-ice model (black) and equivalent reconstruction using the AMO, GBI and Denmark Strait ice flux. RH column, bottom: as top, but for MIROC4h equivalent indices.

a low-frequency influence of SST, linked to the largerscale North Atlantic climate conditions; however, since the time series are characterised only by a low number of degrees of freedom, longer time series should be used to evaluate this more robustly. Using output from the 34-year ice-ocean model simulation and the MIROC4h fully-coupled model, ice export from the Arctic appears to act as a further control by determining the availability of sea ice along the southeast Greenland coast to be exported offshore, and combining the lagged AMO and GBI indices with this quantity it is possible to achieve very strong correlation with the Labrador Sea ice cover of the following winter.
Although we have examined only one CMIP5 model, good consistency is found between the mechanisms inferred using observational data and the coupled iceocean model and the results obtained using the fullycoupled model. This suggests that the variability produced by such models can be, at least, a coherent representation of that inferred from other data sources. However, the spatial resolution of the MIROC4h model examined here is comparatively high, and the MIROC family of models produce a reasonable representation of the NAO and atmospheric blocking conditions (Davini and Cagnazzo, 2014). This is not the case for all fullycoupled models, and we have not investigated the sensi- 
tivity to these conditions. Nevertheless, the consistency found here is encouraging.

The dependence of the ice cover on fresh water (and, at multidecadal time scales, temperature) inferred in this work suggests that strong freshwater input to the region could drive regionally enhanced ice cover in the Labrador Sea were, for example, large quantities of Greenland ice sheet melt water to be advected into the region. As noted by recent studies (e.g. Dukhovskoy et al, 2016, Luo et al, 2016), however, the pathway of the melt water may be dependent on the discharge location, and thus this may be a condition on its influence on Labrador sea ice variability.

Finally, despite the reasonable correlation with the NAO found with the Labrador Sea SIA, we note that the multiannual variability appears to be determined by a sequence of localised processes that are consistent with the greater skill of Greenland blocking in describing the sea ice variability. Whilst this sequence is initiated by conditions that are associated with enhanced westerly winds, the multiple processes implicated suggest that even if the NAO (or Greenland blocking) can act as a trigger, the initial signal is modified by these multiple interactions. This supports the notion that the variability of the Labrador Sea is independent from that of the rest of the Arctic (e.g. Chen et al, 2016, Close et al, 2017), being determined by processes occurring over small spatial regions, and, in combination with the secondary control by the AMO inferred here, suggests that the NAO is not sufficient in itself to predict the regional climate.

\section{A Estimations of freshwater input required to drive salinity changes}

Consider the equation of conservation of salt:

$S_{r}=\frac{\rho_{w} V_{w} S_{w}+\rho_{f} V_{f} S_{f}}{\rho_{w}\left(V_{w}+V_{f}\right)}$,

where $\rho, V$ and $S$ denote density, volume and salinity respectively, and the subscripts $w, f$ and $r$ are used to denote the properties of the source water, the freshwater input and the resultant admixture respectively. We wish to solve for $V_{f}$ and thus rearrange (1) to give:

$V_{f}=\frac{\rho_{w} V_{w}\left(S_{w}-S_{r}\right)}{\rho_{w} S_{r}-\rho_{f} S_{f}}$

We consider the full northern subregion as the source water, and calculate the mean density over this region over the full period to obtain $\rho_{w}=1027.3 \mathrm{~kg} \mathrm{~m}^{-3}$ (with a range of $\pm 0.2 \mathrm{~kg} \mathrm{~m}^{-3}$ about this value). $V_{w}$ is estimated by multiplying the surface area of the northern subregion by a characteristic layer depth. This depth is found by evaluating the correlation between the time series of the JFM surface salinity of the region and that of the underlying depth levels. Decorrelation occurs at a depth of approximately $50 \mathrm{~m}$, yielding a value of $V_{w}=2.565 \times 10^{4} \mathrm{~km}^{3}$ for the source water volume. We then take the mean salinity of the northern subregion in October as $S_{w}$ (the month after which the correlation between the summer/autumn and winter SSS in the region breaks down), and the mean salinity over the region in January (the time at which ice growth is underway) as the target admixture, $S_{r}$.

In a first step, we consider the freshwater input necessary to effect the observed salinity change, and thus use $S_{f}=0$. From (2), we estimate the freshwater volume $V_{f}$, required to drive the salinity change in each year. The average freshwater input required for the highest quartile of SIA years is thus $130 \mathrm{~km}^{3} / \mathrm{yr}$ (with a maximum required input of $390 \mathrm{~km}^{3} / \mathrm{yr}$ ).

In a second step, we take into account the increased salinity of the ice meltwater. Since the salinity data are model outputs, we use the values of $\rho_{f}$ and $S_{f}$ employed by the ice model to preserve a consistent framework, thus taking $\rho_{f}=900 \mathrm{~kg} \mathrm{~m}^{-3}$ and $S_{f}=6$. With these values, a mean required input of $\sim 150 \mathrm{~km}^{3} / \mathrm{yr}$ is obtained (with a maximum of $\left.460 \mathrm{~km}^{3} / \mathrm{yr}\right)$.

\section{B Estimates of influence of glacial meltwater}

Drawing on Figure SI1 of Bamber et al (2012), the difference between highest and lowest meltwater fluxes over the 19791998 period is approximately $40 \mathrm{~km}^{3} / \mathrm{yr}$. Using this value as $V_{f}$ in 11 above, and using the mean surface salinity over the study period, $S_{w}=33.9$ (again, using the October mean SSS value and model output, with all other parameters as above), this would imply a change of 0.04 in salinity were the full volume of meltwater to be mixed over the northern subregion. For comparison, both the model and EN4 objective analysis suggest that the large freshening episodes corresponding to the high ice cover states were associated with a decrease in salinity of order 0.5 .

Acknowledgements We acknowledge the World Climate Research Programme's Working Group on Coupled Modelling, which is responsible for CMIP, and we thank the Atmosphere and Ocean Research Institute (The University of Tokyo), National Institute for Environmental Studies, and Japan Agency for Marine-Earth Science and Technology for producing and making available their model output. For CMIP the U.S. Department of Energy's Program for Climate Model Diagnosis and Intercomparison provides coordinating support and led development of software infrastructure in partnership with the Global Organization for Earth System Science Portals. We are grateful to the three anonymous reviewers for their helpful comments on the manuscript.

\section{References}

Aagaard K, Carmack EC (1989) The role of sea ice and other fresh water in the Arctic circulation. J Geophys Res 94(C10):14,485-14,498, DOI 10.1029/JC094iC10p14485/ full

Bakalian F, Hameed S, Pickart R (2007) Influence of the Icelandic Low latitude on the frequency of Greenland tip jet events: Implications for Irminger Sea convection. J Geophys Res 112(C4), DOI 10.1029/2006JC003807, c04020

Bamber J, van den Broeke M, Ettema J, Lenaerts J, Rignot E (2012) Recent large increases in freshwater fluxes from Greenland into the north atlantic. Geophys Res Lett 39(19), DOI 10.1029/2012GL052552, 119501 
Bamber JL, Layberry RL, Gogineni SP (2001) A new ice thickness and bed data set for the Greenland ice sheet: 1 . Measurement, data reduction, and errors. Journal of Geophysical Research: Atmospheres 106(D24):33,773-33,780, DOI 10.1029/2001JD900054

Barnes EA (2013) Revisiting the evidence linking arctic amplification to extreme weather in midlatitudes. Geophys Res Lett 40(17):4734-4739, DOI 10.1002/grl.50880

Barnes EA, Dunn-Sigouin E, Masato G, Woollings T (2014) Exploring recent trends in northern hemisphere blocking. Geophys Res Lett 41(2):638-644, DOI 10.1002/ 2013GL058745

Belkin IM (2004) Propagation of the "Great Salinity Anomaly" of the 1990s around the northern North Atlantic. Geophys Res Lett 31(8), DOI 10.1029/ 2003GL019334, 108306

Belkin IM, Levitus S, Antonov J, Malmberg SA (1998) "Great Salinity Anomalies" in the North Atlantic. Progress in Oceanography 41(1):1-68, DOI 10.1016/S0079-6611(98) 00015-9

Bitz CM, Holland MM, Hunke EC, Moritz RE (2005) Maintenance of the Sea-Ice Edge. J Climate 18(15):2903-2921, DOI 10.1175/JCLI3428.1

Boning CW, Behrens E, Biastoch A, Getzlaff K, Bamber JL (2016) Emerging impact of Greenland meltwater on deepwater formation in the north atlantic ocean. Nature Geosci 9(7):523-527, DOI 10.1038/ngeo2740

Chelton DB (1983) Effects of sampling errors in statistical estimation. Deep Sea Res A 30(10):1083-1103, DOI 10. 1016/0198-0149(83)90062-6

Chen HW, Alley RB, Zhang F (2016) Interannual Arctic sea ice variability and associated winter weather patterns: A regional perspective for 1979-2014. Journal of Geophysical Research: Atmospheres DOI 10.1002/2016JD024769, 2016JD024769

Close S, Houssais MN, Herbaut C (2015) Regional dependence in the timing of onset of rapid decline in Arctic sea ice concentration. J Geophys Res 120(12):8077-8098, DOI 10.1002/2015JC011187

Close S, Houssais MN, Herbaut C (2017) The Arctic Winter Sea Ice Quadrupole Revisited. J Climate in press, DOI 10.1175/JCLI-D-16-0506.1

Cohen J, Screen JA, Furtado JC, Barlow M, Whittleston D, Coumou D, Francis J, Dethloff K, Entekhabi D, Overland J, Jones J (2014) Recent Arctic amplification and extreme mid-latitude weather. Nature Geosci 7(9):627-637, DOI $10.1038 /$ ngeo 2234

Comiso JC (2000, updated 2014) Bootstrap Sea Ice Concentrations from Nimbus-7 SMMR and DMSP SSM/I-SSMIS. Version 2. DOI 10.5067/J6JQLS9EJ5HU

Davini P, Cagnazzo C (2014) On the misinterpretation of the North Atlantic Oscillation in CMIP5 models. Climate Dyn 43(5-6):1497-1511, DOI 10.1007/s00382-013-1970-y

Davini P, Cagnazzo C, Gualdi S, Navarra A (2012a) Bidimensional Diagnostics, Variability, and Trends of Northern Hemisphere Blocking. J Climate 25(19):6496-6509, DOI 10.1175/JCLI-D-12-00032.1

Davini P, Cagnazzo C, Neale R, Tribbia J (2012b) Coupling between Greenland blocking and the North Atlantic Oscillation pattern. Geophys Res Lett 39(14), DOI 10.1029/ 2012GL052315

Dee DP, Uppala SM, Simmons AJ, Berrisford P, Poli P, Kobayashi S, Andrae U, Balmaseda MA, Balsamo G, Bauer P, Bechtold P, Beljaars ACM, van de Berg L, Bidlot J, Bormann N, Delsol C, Dragani R, Fuentes M, Geer AJ, Haimberger L, Healy SB, Hersbach H, Hólm EV, Isaksen L,
Källberg P, Köhler M, Matricardi M, McNally AP, MongeSanz BM, Morcrette JJ, Park BK, Peubey C, de Rosnay P, Tavolato C, Thépaut JN, Vitart F (2011) The ERAInterim reanalysis: configuration and performance of the data assimilation system. QJR Meteorol Soc 137(656):553597, DOI 10.1002/qj.828

Deser C, Walsh JE, Timlin MS (2000) Arctic Sea Ice Variability in the Context of Recent Atmospheric Circulation Trends. J Climate 13(3):617-633, DOI 10.1175/15200442(2000)013\$ $\$ \$ 0617$ :ASIVIT $\$\rangle 2.0 . \mathrm{CO} ; 2$

Deser C, Holland M, Reverdin G, Timlin M (2002) Decadal variations in Labrador Sea ice cover and North Atlantic sea surface temperatures. J Geophys Res 107(C5):3-1-312, DOI 10.1029/2000JC000683

Doyle J, Shapiro M (1999) Flow response to large-scale topography: the Greenland tip jet. Tellus A 51(5)

Dukhovskoy DS, Myers PG, Platov G, Timmermans ML, Curry B, Proshutinsky A, Bamber JL, Chassignet E, Hu X, Lee CM, Somavilla R (2016) Greenland freshwater pathways in the sub-Arctic Seas from model experiments with passive tracers. Journal of Geophysical Research: Oceans 121(1):877-907, DOI 10.1002/2015JC011290

Fang Z, Wallace JM (1994) Arctic Sea Ice Variability on a Timescale of Weeks and Its Relation to Atmospheric Forcing. J Climate 7(12):1897-1914, DOI 10.1175/15200442(1994)007\$ $\$ 1897$ :ASIVOA $\$>2.0 . \mathrm{CO} ; 2$

Fang ZF (2012) Statistical relationship between the northern hemisphere sea ice and atmospheric circulation during wintertime, World Scientific, pp 131-141. DOI 10.1142/ 9789812791139\_0006

Fenty I, Heimbach P (2013) Hydrographic Preconditioning for Seasonal Sea Ice Anomalies in the Labrador Sea. J Phys Oceanogr 43(5):863-883, DOI 10.1175/JPO-D-12-064.1

Fichefet T, Maqueda MAM (1997) Sensitivity of a global sea ice model to the treatment of ice thermodynamics and dynamics. J Geophys Res 102(C6):12,609-12,646, DOI 10.1029/97JC00480

Good SA, Martin MJ, Rayner NA (2013) EN4: Quality controlled ocean temperature and salinity profiles and monthly objective analyses with uncertainty estimates. J Geophys Res 118(12):6704-6716, DOI 10.1002/2013JC009067

Goosse H, Selten F, Haarsma R, Opsteegh J (2002) A mechanism of decadal variability of the sea-ice volume in the Northern Hemisphere. Climate Dyn 19(1):61-83, DOI 10.1007/s00382-001-0209-5

Häkkinen S (1993) An arctic source for the great salinity anomaly: A simulation of the arctic ice-ocean system for 1955-1975. Journal of Geophysical Research: Oceans 98(C9):16,397-16,410, DOI 10.1029/93JC01504

Häkkinen S (2002) Freshening of the Labrador Sea surface waters in the 1990s: Another great salinity anomaly? Geophys Res Lett 29(24):85-1-85-4, DOI 10.1029/2002GL015243, 2232

Hanna E, Jones JM, Cappelen J, Mernild SH, Wood L, Steffen K, Huybrechts P (2013) The influence of North Atlantic atmospheric and oceanic forcing effects on 1900-2010 Greenland summer climate and ice melt/runoff. Int J Climatol 33(4):862-880, DOI 10.1002/joc.3475

Hanna E, Cropper TE, Hall RJ, Cappelen J (2016) Greenland Blocking Index 1851-2015: a regional climate change signal. International Journal of Climatology 36(15):48474861, DOI $10.1002 /$ joc. 4673

Herbaut C, Houssais MN, Close S, Blaizot AC (2015) Two wind-driven modes of winter sea ice variability in the Barents Sea. Deep Sea Res I 106:97-115, DOI 10.1016/j.dsr. 2015.10.005 
Hodson D, Sutton R (2012) The impact of resolution on the adjustment and decadal variability of the atlantic meridional overturning circulation in a coupled climate model. Clim Dyn 39:3057, DOI 10.1007/s00382-012-1309-0

Ikeda M, Symonds G, Yao T (1988) Simulated fluctuations in annual Labrador sea ice cover. Atmosphere-Ocean 26(1):16-39, DOI 10.1080/07055900.1988.9649287

Jackson LC, Peterson KA, Roberts CD, Wood RA (2016) Recent slowing of Atlantic overturning circulation as a recovery from earlier strengthening. Nature Geosci 9:518522, DOI 10.1038/ngeo2715

Jungclaus JH, Haak H, Latif M, Mikolajewicz U (2005) Arctic-North Atlantic Interactions and Multidecadal Variability of the Meridional Overturning Circulation. J Climate 18(19):4013-4031, DOI 10.1175/JCLI3462.1

Karcher M, Gerdes R, Kauker F, Köberle C, Yashayaev I (2005) Arctic Ocean change heralds North Atlantic freshening. Geophys Res Lett 32(21), DOI 10.1029/ 2005GL023861, 121606

Kuhlbrodt T, Titz S, Feudel U, Rahmstorf S (2001) A simple model of seasonal open ocean convection. Part II: Labrador Sea stability and stochastic forcing. Ocean Dynamics 52(1):36-49, DOI 10.1007/s10236-001-8175-3

Kvamst $\varnothing$ NG Nils Gunnar, Skeie P, Stephenson DB (2004) Impact of Labrador sea-ice extent on the North Atlantic oscillation. International Journal of Climatology 24(5):603612 , DOI $10.1002 /$ joc. 1015

Lozier MS (2012) Overturning in the north atlantic. Annual Review of Marine Science 4(1):291-315, DOI 10.1146/ annurev-marine-120710-100740, pMID: 22457977

Luo H, Castelao RM, Rennermalm AK, Tedesco M, Bracco A, Yager PL, Mote TL (2016) Oceanic transport of surface meltwater from the southern Greenland ice sheet. Nature Geosci 9(7):528-532, DOI 10.1038/ngeo2708

Madec G (2008) NEMO ocean engine. Note du pôle de modélisation 27, Institut Pierre Simon Laplace (IPSL), France

Marsden RF, Mysak LA, Myers RA (1991) Evidence for stability enhancement of sea ice in the Greenland and Labrador Seas. Journal of Geophysical Research: Oceans 96(C3):4783-4789, DOI 10.1029/90JC02272

Marshall J, Schott F (1999) Open-ocean convection: Observations, theory, and models. Rev Geophys 37(1):1-64, DOI 10.1029/98RG02739

Marshall J, Dobson F, Moore K, Rhines P, Visbeck M, d'Asaro E, Bumke K, Chang S, Davis R, Fischer K, Garwood R, Guest P, Harcourt R, Herbaut C, Holt T, Lazier J, Legg S, McWilliams J, Pickart R, Prater M, Renfrew I, Schott F, Send U, Smethie W (1998) The Labrador Sea Deep Convection Experiment. Bull Amer Meteor Soc 79(10):2033-2058, DOI 10.1175/1520-0477(1998)079<2033: TLSDCE $>2.0 . \mathrm{CO} ; 2$

Moore GWK (2003) Gale force winds over the irminger sea to the east of cape farewell, Greenland. Geophys Res Lett 30(17), DOI 10.1029/2003GL018012, 1894

Moore GWK, Renfrew IA (2005) Tip Jets and Barrier Winds: A QuikSCAT Climatology of High Wind Speed Events around Greenland. J Climate 18(18):3713-3725, DOI 10.1175/JCLI3455.1

Moore GWK, Renfrew IA, Pickart RS (2013) Multidecadal Mobility of the North Atlantic Oscillation. J Climate 26(8):2453-2466, DOI 10.1175/JCLI-D-12-00023.1

Moore GWK, Straneo F, Oltmanns M (2014) Trend and interannual variability in southeast Greenland Sea Ice: Impacts on coastal Greenland climate variability. Geophys Res Lett 41(23):8619-8626, DOI 10.1002/2014GL062107,
2014GL062107

Moore GWK, Vage K, Pickart RS, Renfrew IA (2015) Decreasing intensity of open-ocean convection in the Greenland and Iceland seas. Nature Clim Change 5(9):877-882, DOI 10.1038/nclimate2688

Mysak L, Manak D, Marsden R (1990) Sea-ice anomalies observed in the Greenland and Labrador seas during 1901-1984 and their relation to an interdecadal Arctic climate cycle. Climate Dyn 5(2):111-133, DOI 10.1007/ BF00207426

Mysak L, Ingram R, Wang J, van der Baaren A (1996) The anomalous sea ice extent in Hudson bay, Baffin bay and the Labrador sea during three simultaneous NAO and ENSO episodes. Atmosphere-Ocean 34(2):313-343, DOI 10.1080/ 07055900.1996.9649567

Mysak LA, Manak DK (1989) Arctic Sea-Ice extent and anomalies, 1953-1984. Atmosphere-Ocean 27(2):376-405, DOI 10.1080/07055900.1989.9649342

Oltmanns M, Straneo F, Moore GWK, Mernild SH (2014) Strong Downslope Wind Events in Ammassalik, Southeast Greenland. J Climate 27(3):977-993, DOI 10.1175/JCLID-13-00067.1

Oltmanns M, Straneo F, Seo H, Moore GWK (2015) The Role of Wave Dynamics and Small-Scale Topography for Downslope Wind Events in Southeast Greenland. J Atmos Sci 72(7):2786-2805, DOI 10.1175/JAS-D-14-0257.1

Peterson I, Pettipas R, Rosing-Asvid A (2015) Trends and Variability in Sea Ice and Icebergs off the Canadian East Coast. Atmosphere-Ocean 53(5):582-594, DOI 10.1080/ 07055900.2015 .1057684

Pickart RS, Spall MA (2007) Impact of labrador sea convection on the north atlantic meridional overturning circulation. J Phys Oceanogr 37(9):2207-2227, DOI 10.1175/ JPO3178.1

Pickart RS, Torres DJ, Clarke RA (2002) Hydrography of the Labrador Sea during Active Convection. J Phys Oceanogr 32(2):428-457, DOI 10.1175/1520-0485(2002) 032 $20428:$ HOTLSD $\rangle 2.0 . \mathrm{CO} ; 2$

Pickart RS, Spall MA, Ribergaard MH, Moore GWK, Milliff RF (2003) Deep convection in the Irminger Sea forced by the Greenland tip jet. Nature 424(6945):152-156, DOI 10. 1038/nature01729

Poli P, Hersbach H, Dee DP, Berrisford P, Simmons AJ, Vitart F, Laloyaux P, Tan DGH, Peubey C, Thépaut JN, Trémolet Y, Hólm EV, Bonavita M, Isaksen L, Fisher M (2016) ERA-20C: An Atmospheric Reanalysis of the Twentieth Century. J Climate 29(11):4083-4097, DOI 10.1175/JCLI-D-15-0556.1

Prinsenberg SJ, Peterson IK, Narayanan S, Umoh JU (1997) Interaction between atmosphere, ice cover, and ocean off Labrador and Newfoundland from 1962 to 1992. Can J Fish Aquat Sci 54(S1):30-39, DOI 10.1139/f96-150

Rex DF (1950) Blocking action in the middle troposphere and its effect upon regional climate. Tellus 2(4):275-301, DOI $10.1111 / \mathrm{j} .2153-3490.1950 . t b 00339 . x$

Reynolds RW, Smith TM, Liu C, Chelton DB, Casey KS, Schlax MG (2007) Daily High-Resolution-Blended Analyses for Sea Surface Temperature. J Climate 20(22):54735496, DOI 10.1175/2007JCLI1824.1

Roberts CD, Garry FK, Jackson LC (2013) A multimodel study of sea surface temperature and subsurface density fingerprints of the atlantic meridional overturning circulation. J Climate 26(22):9155-9174, DOI 10.1175/JCLI-D12-00762.1

Robson J, Hodson D, Hawkins E, Sutton R (2014) Atlantic overturning in decline? Nature Geosci 7(1):2-3, DOI 10. 
$1038 /$ ngeo2050

Rogers JC, van Loon H (1979) The Seesaw in Winter Temperatures between Greenland and Northern Europe. Part II: Some Oceanic and Atmospheric Effects in Middle and High Latitudes. Mon Wea Rev 107(5):509-519, DOI 10. 1175/1520-0493(1979)107〈0509:TSIWTB $\rangle 2.0 . C O ; 2$

Sakamoto TT, Komuro Y, Nishimura T, Ishii M, Tatabe H, Shiogama H, Hasegawa A, Toyoda T, Mori M, Suzuki T, Imada Y, Nozawa T, Takata K, Mochizuki T, Ogochi K, Emori S, Hasumi H, Kimoto M (2012) MIROC4h: A new high-resolution atmosphere-ocean coupled general circulation model. Journal of the Meteorological Society of Japan Ser II 90(3):325-359, DOI 10.2151/jmsj.2012-301

Screen JA, Deser C, Simmonds I, Tomas R (2014) Atmospheric impacts of Arctic sea-ice loss, 1979-2009: separating forced change from atmospheric internal variability. Climate Dyn 43(1-2):333-344, DOI 10.1007/s00382-013-18309

Seierstad IA, Bader J (2008) Impact of a projected future arctic sea ice reduction on extratropical storminess and the nao. Climate Dyn 33(7):937, DOI 10.1007/s00382-0080463-x

Slonosky VC, Mysak LA, Derome J (1997) Linking Arctic sea ice and atmospheric circulation anomalies on interannual and decadal timescales. Atmosphere-Ocean 35(3):333-366, DOI 10.1080/07055900.1997.9649596

Straneo F, Heimbach P (2013) North Atlantic warming and the retreat of Greenland's outlet glaciers. Nature 504(7478):36-43, DOI 10.1038/nature12854

Strong C, Magnusdottir G, Stern H (2009) Observed feedback between winter sea ice and the north atlantic oscillation. $\mathrm{J}$ Climate 22(22):6021-6032, DOI 10.1175/2009JCLI3100.1

Talley LD, Reid JL, Robbins PE (2003) Data-Based Meridional Overturning Streamfunctions for the Global Ocean. J Climate 16(19):3213-3226, DOI 10.1175/1520-0442(2003) 016<3213:DMOSFT $>2.0 . \mathrm{CO} ; 2$

Taylor KE, Stouffer RJ, Meehl GA (2011) An Overview of CMIP5 and the Experiment Design. Bull Amer Meteor Soc 93(4):485-498, DOI 10.1175/BAMS-D-11-00094.1

Titchner HA, Rayner NA (2014) The met office hadley centre sea ice and sea surface temperature data set, version 2: 1. sea ice concentrations. Journal of Geophysical Research: Atmospheres 119(6):2864-2889, DOI 10.1002/ 2013JD020316, 2013JD020316

Tschudi M, Fowler C, Maslanik J, Stewart JS, Meier W (2016) Polar Pathfinder Daily $25 \mathrm{~km}$ EASE-Grid Sea Ice Motion Vectors. Version 3. Tech. rep., National Snow and Ice Data Center, Boulder, Colorado USA, DOI 10.5067/ O57VAIT2AYYY

Våge K, Pickart RS, Moore GWK, Ribergaard MH (2008) Winter Mixed Layer Development in the Central Irminger Sea: The Effect of Strong, Intermittent Wind Events. J Phys Oceanogr 38(3):541-565, DOI 10.1175/ 2007JPO3678.1

Våge K, Pickart RS, Thierry V, Reverdin G, Lee CM, Petrie B, Agnew TA, Wong A, Ribergaard MH (2009a) Surprising return of deep convection to the subpolar North Atlantic Ocean in winter 2007-2008. Nature Geosci 2(1):67-72, DOI $10.1038 /$ ngeo382

Våge K, Spengler T, Davies HC, Pickart RS (2009b) Multievent analysis of the westerly Greenland tip jet based upon 45 winters in ERA-40. Quart J Roy Meteor Soc 135(645):1999-2011, DOI 10.1002/qj.488

Visbeck M, Fischer J, Schott F (1995) Preconditioning the Greenland Sea for deep convection: Ice formation and ice drift. J Geophys Res 100(C9):18,489-18,502, DOI 10.1029/
95JC01611

Walsh JE, Chapman WL (1990) Arctic contribution to upper-ocean variability in the north atlantic. J Climate 3(12):1462-1473, DOI 10.1175/1520-0442(1990)003〈1462: ACTUOV $>2.0 . \mathrm{CO} ; 2$

Walsh JE, Johnson CM (1979) Interannual atmospheric variability and associated fluctuations in Arctic Sea ice extent. J Geophys Res 84(C11):6915-6928, DOI 10.1029/ JC084iC11p06915

Wang J, Mysak LA, Ingram RG (1994) Interannual variability of seaâice cover in Hudson bay, Baffin bay and the Labrador sea. Atmosphere-Ocean 32(2):421-447, DOI 10.1080/07055900.1994.9649505

Woollings T, Hoskins B, Blackburn M, Berrisford P (2008) A New Rossby Wave-Breaking Interpretation of the North Atlantic Oscillation. J Atmos Sci 65(2):609-626, DOI 10. 1175/2007JAS2347.1

Woollings T, Hannachi A, Hoskins B (2010) Variability of the north atlantic eddy-driven jet stream. Quart J Roy Meteor Soc 136(649):856-868, DOI 10.1002/qj.625

Yang Q, Dixon TH, Myers PG, Bonin J, Chambers D, van den Broeke MR (2016) Recent increases in Arctic freshwater flux affects Labrador Sea convection and Atlantic overturning circulation. Nat Commun 7, DOI 10. 1038/ncomms10525

Yashayaev I, Loder JW (2016) Recurrent replenishment of Labrador Sea Water and associated decadal-scale variability. Journal of Geophysical Research: Oceans DOI 10.1002/2016JC012046 


\section{Figures}

SI1 \% of variance explained by regression of SSMI SIC on to JFM SIA of (a) total region, (b) thermodynamically-influenced subregion, (c) remainder obtained by subtracting SIA of subregion from total. (d) SIA time series used in regressions. In (a-c), the thick black contour shows the points used to define the northern subregion. . . . . . . . 2

SI2 (a) \% of variance explained by regression of thermodynamically-influenced subregion on to OND ice velocity. (b) \% of variance explained by regression of the remainder obtained by subtracting the SIA of the subregion from the total on to the NDJ ice velocity. . . . . . . . . 2

SI3 Regression onto ERA20C JFM SIC of (a) northern and (b) southern subregion SIA (JFM). (c) JFM SIA time series for total regional SIA (black solid line), northern subregion SIA (solid grey line) and southern subregion SIA (dashed grey line). (d) \% variance explained in ERA20C total DJF heat flux by northern subregion SIA. (e) Difference between composites of 0-2700 m mean NDJF winds constructed using years in the upper and lower quartiles of northern subregion SIA. 3

SI4 \% of variance explained by regression onto MIROC4h northern subregion SIA (1950-2005) of (a) NDJ 1 m depth salinity, (b) NDJ water flux into ocean due to sea ice thermodynamics and (c) DJF geopotential height at $500 \mathrm{hPa}$. (d) JFM SIA time series of full region (black) and northern subregion (grey) in MIROC4h. . . . . . . . . . . . 4 

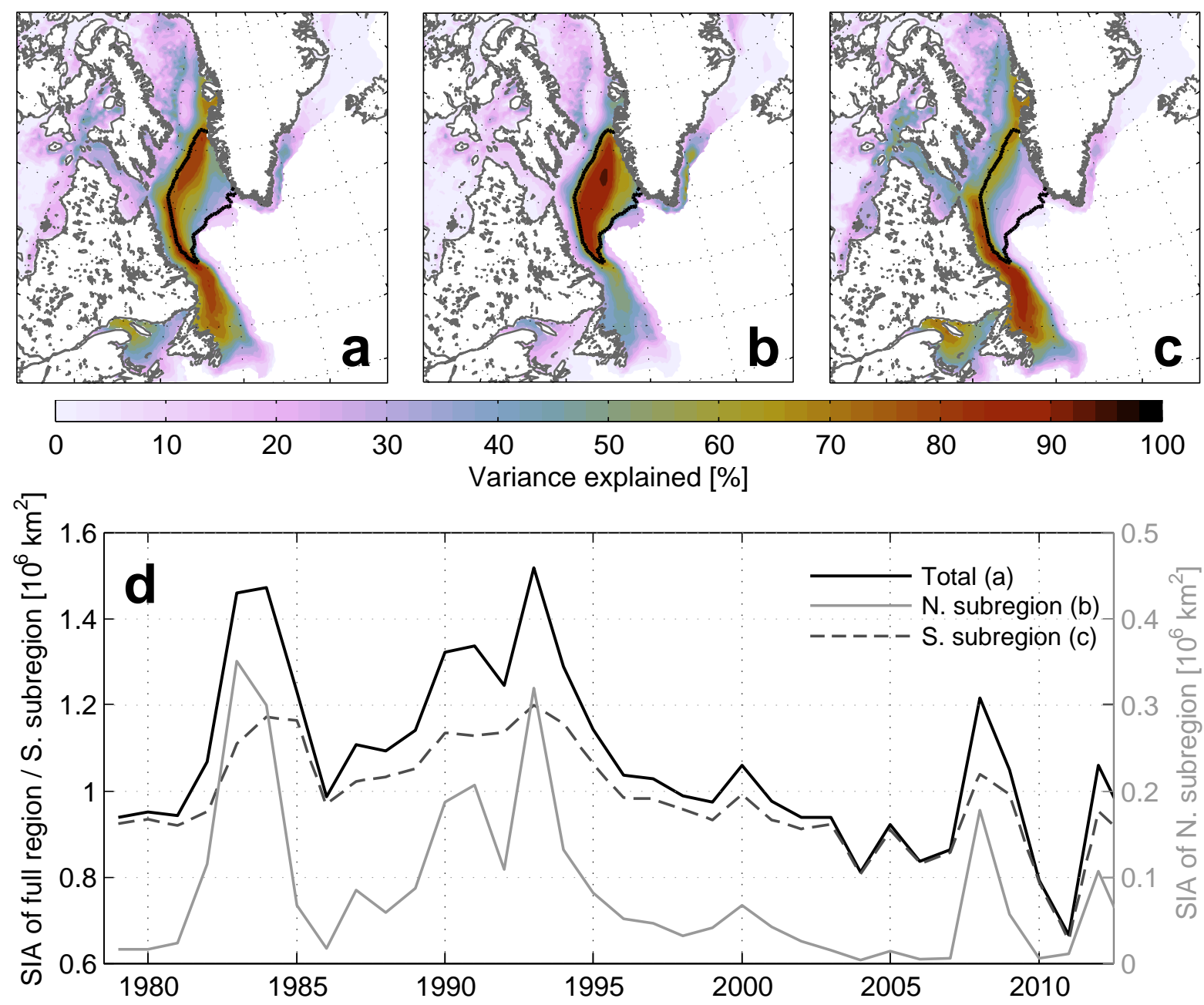

Figure SI1: \% of variance explained by regression of SSMI SIC on to JFM SIA of (a) total region, (b) thermodynamically-influenced subregion, (c) remainder obtained by subtracting SIA of subregion from total. (d) SIA time series used in regressions. In (a-c), the thick black contour shows the points used to define the northern subregion.
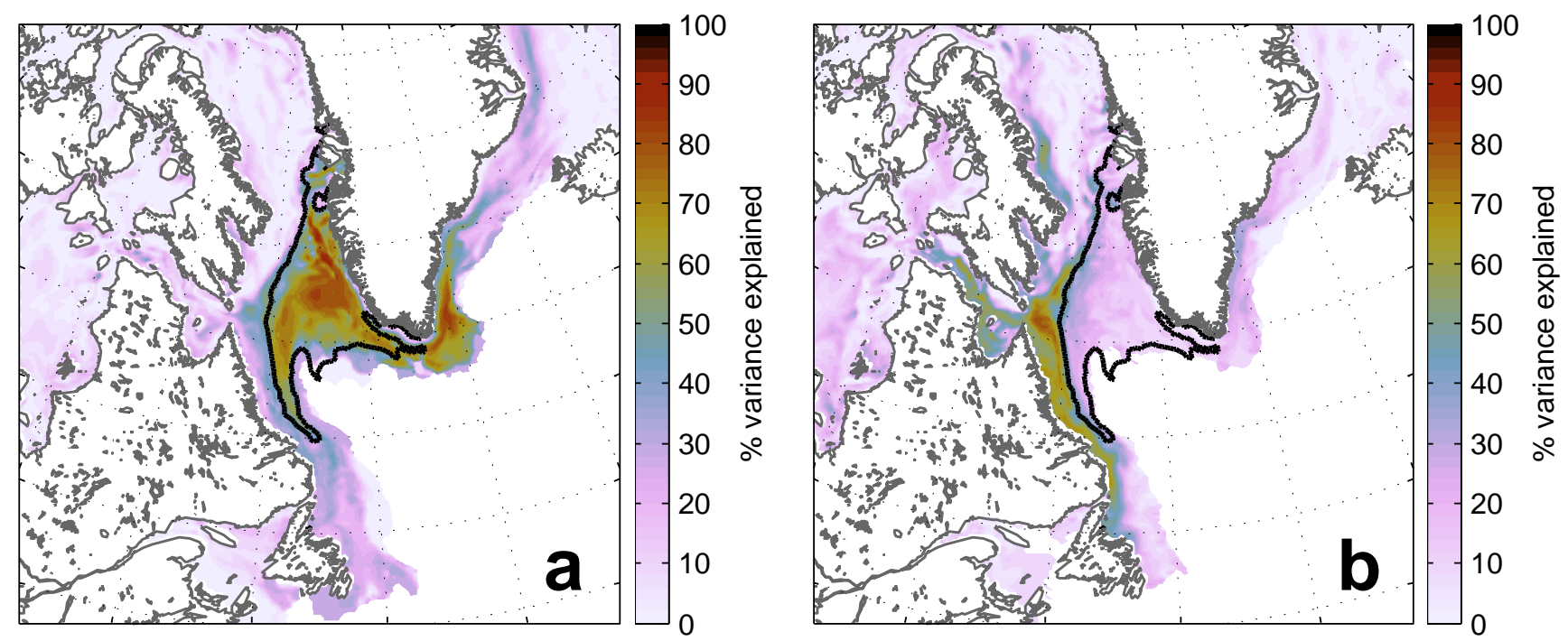

Figure SI2: (a) \% of variance explained by regression of thermodynamically-influenced subregion on to OND ice velocity. (b) \% of variance explained by regression of the remainder obtained by subtracting the SIA of the subregion from the total on to the NDJ ice velocity. 

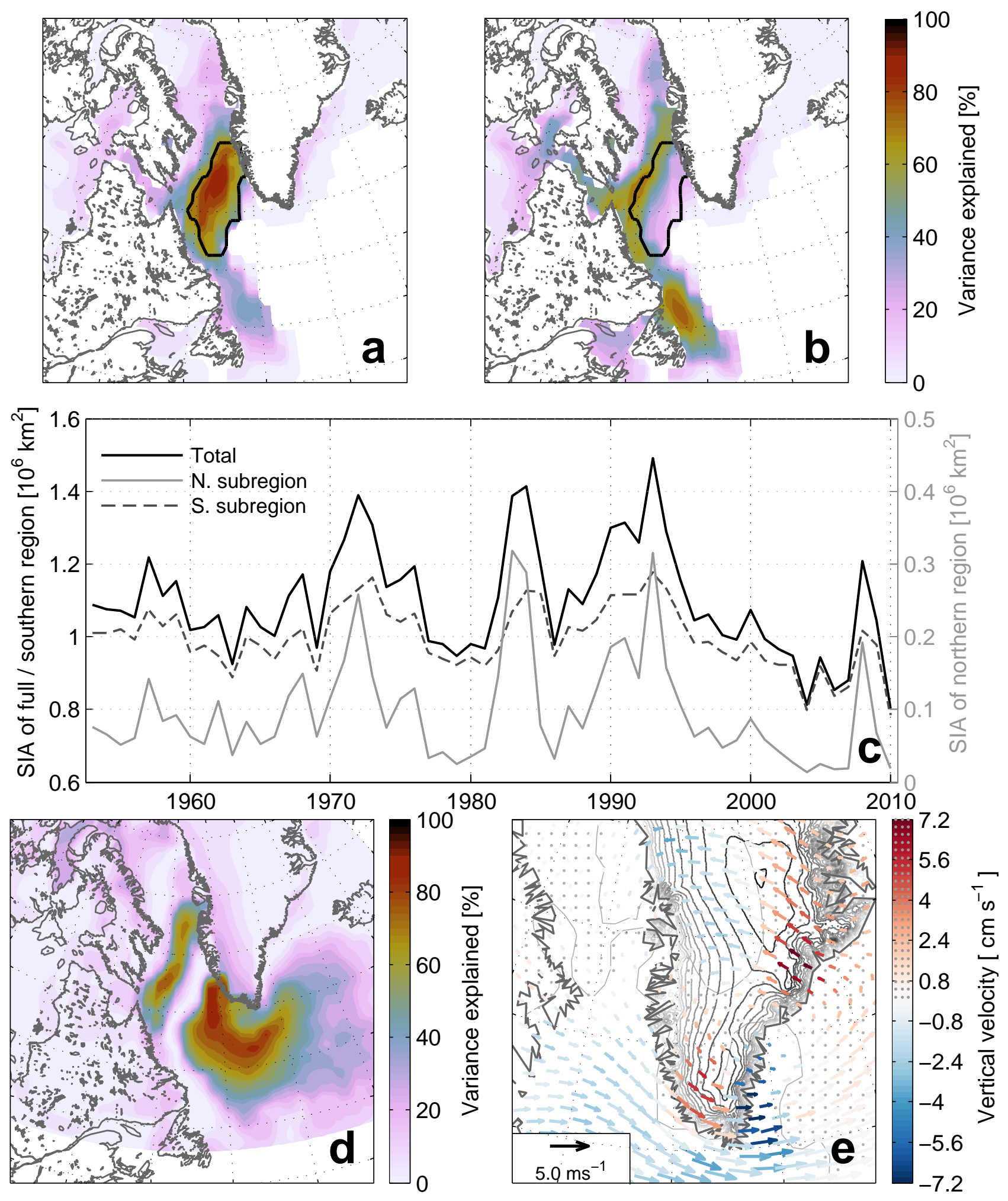

Figure SI3: Regression onto ERA20C JFM SIC of (a) northern and (b) southern subregion SIA (JFM). (c) JFM SIA time series for total regional SIA (black solid line), northern subregion SIA (solid grey line) and southern subregion SIA (dashed grey line). (d) \% variance explained in ERA20C total DJF heat flux by northern subregion SIA. (e) Difference between composites of 0-2700 m mean NDJF winds constructed using years in the upper and lower quartiles of northern subregion SIA. 


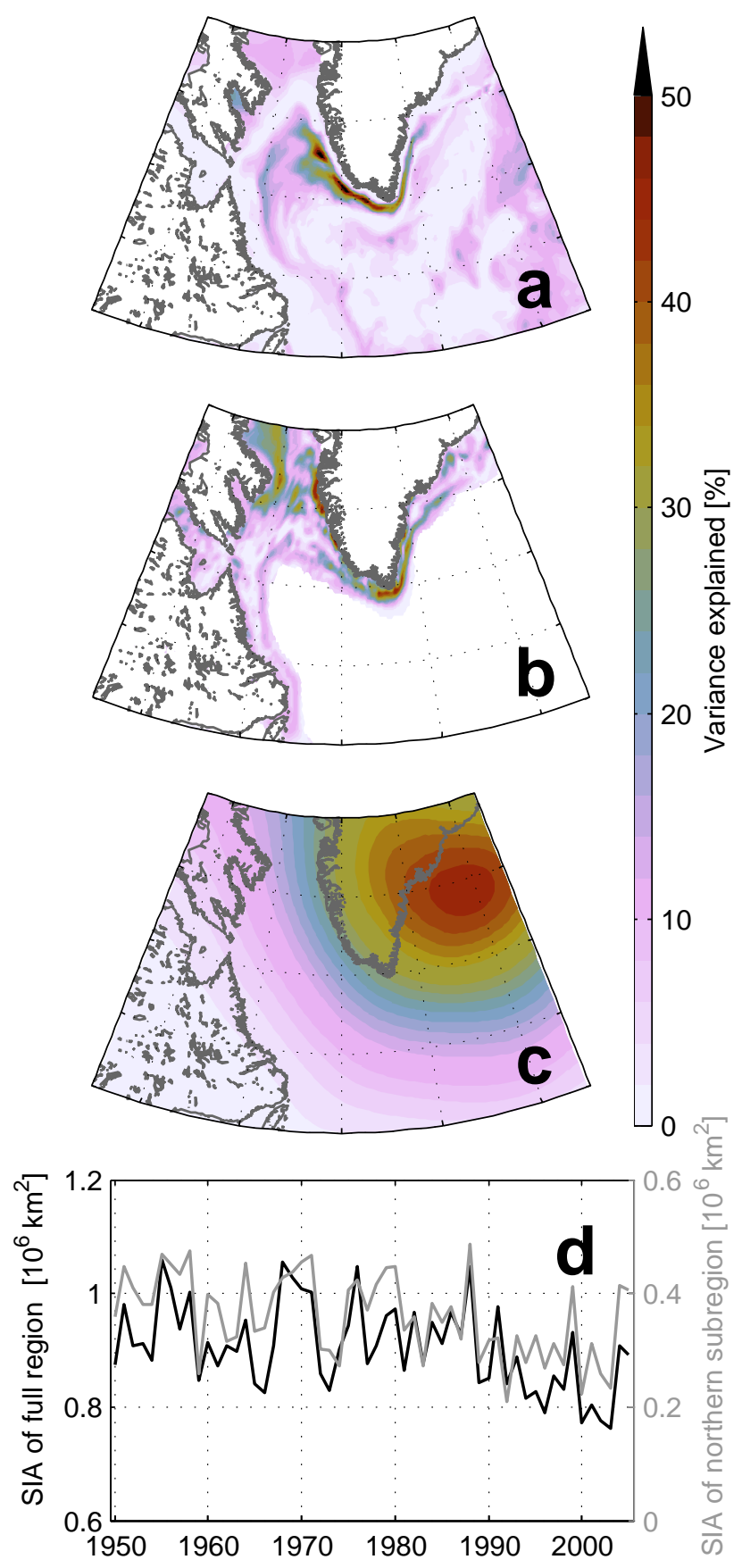

Figure SI4: \% of variance explained by regression onto MIROC4h northern subregion SIA (1950-2005) of (a) NDJ $1 \mathrm{~m}$ depth salinity, (b) NDJ water flux into ocean due to sea ice thermodynamics and (c) DJF geopotential height at $500 \mathrm{hPa}$. (d) JFM SIA time series of full region (black) and northern subregion (grey) in MIROC4h. 